\title{
Informational primacy of visual dimensions: Specialized roles for luminance and chromaticity in figure-ground perception
}

\author{
NORIKO YAMAGISHI and ROBERT D. MELARA \\ Purdue University, West Lafayette, Indiana
}

\begin{abstract}
Three experiments were conducted to examine the distinct contributions of two visual dimensions to figure-ground segregation. In each experiment, pattern identification was assessedby asking observers to judge whether a near-threshold test pattern was the same or different in shape to a high-contrast comparison pattern. A test pattern could differ from its background along one dimension, either luminance (luminance tasks) or chromaticity (chromaticity tasks). In each task, performance in a baseline condition, in which the test pattern was intact, was compared with performance in each of several degradation conditions, in which either the contour or the surface of the figure was degraded, using either partial occlusion (Experiment 1) or ramping (Experiments 2 and 3) of figure-ground differences. In each experiment, performance in luminance tasks was worst when the contour was degraded, whereas performance in chromaticity tasks was worst when the surface was degraded. This interaction was found even when spatial frequencies were fixed across test patterns by low-pass filtering. The results are consistent with a late (postfiltering) dual-mechanism system that processes luminance information to extract boundary representations and chromaticity information to extract surface representations.
\end{abstract}

How is a figure distinguished from its ground? Since the Gestalt psychologists posed this question almost a century ago, it has been a subject of continuous scientific scrutiny and steady theoretical progress. Theoretical speculation, which began with the Gestaltists themselves, has been offered at both psychological and physiological levels of explanation. Rubin's (1915) seminal demonstrations of figure-ground perception, for example, initially received a perceptual interpretation: The contours of a figure create a phenomenological whole to which observers instinctively respond. Later, Köhler (1920, 1958; Köhler \& Held, 1949), seeking the biological roots of Rubin's results, conjectured that the flow of neural current is stronger through cortical loci involved in processing of the figure relative to its ground.

Today, in addressing the Gestalt question, researchers focus on the types of information the figure-ground array supplies to the visual system. The array may provide information about figural "goodness" (Attneave, 1954; Garner, 1974) or symmetry (Palmer, 1982, 1991), the array

The experiments reported herein were submitted by N.Y. in partial fulfillment of the requirements for a doctoral degree at Purdue University; her present address is ATR International, Information Sciences Division, 2-2 Hikaridai Seika-cho, Soraku-gun, Kyoto 619-02, Japan. We thank Carol Cicerone and three anonymous reviewers for their helpful comments and suggestions on an earlier version of this article. Special thanks are due Naokazu Goda for his assistance in creating the filtered patterns used in Experiment 3. Correspondence concerning this article should be addressed to R. D. Melara, Department of Psychological Sciences, Purdue University, West Lafayette, IN 47907-1364 (e-mail: melara@psych.purdue.edu). may entail varying degrees of figural uncertainty (Graham, 1989) or figure-ground discriminability (Theeuwes, 1992), or the array may segregate figures by properties of spatial frequency (e.g., Graham, 1980), binocular disparity (e.g., Julesz, 1964), texture (e.g., Beck, 1966), or motion (e.g., D. G. Watson \& Humphreys, 1999; Wertheimer, 1912). At the most basic level, however, the information supplied by the stimulus array is bidimensional: All pictorial cues arise from variation across space in the psychophysical dimensions of luminance and chromaticity. The purpose of the present study was to investigate the separate roles of luminance and chromaticity in distinguishing a figure from its ground.

\section{Surfaces and Boundaries}

Observers can recognize and describe any figure through its properties. For example, one might be required to detect, although perhaps only in a video game, a large, triangular, red and green plaid pattern floating across a clear blue sky. The size, texture, colors, and motion of this figure are the properties by which we identify and define its surface and shape against the ground (Beck, 1982; Julesz, 1984; Treisman \& Gelade, 1980). Yet each of these second-order attributes (Cavanagh, Arguin, \& Treisman, 1990) are themselves derived from discontinuities along the first-order dimensions of luminance and chromaticity. Indeed, the changes in luminance and chromaticity directly create the surface (region) and the boundaries (contour) of the pattern. Thus, a useful level of analysis for understanding figural perception is to study how perceivers use luminance and chromaticity information to isolate the surfaces and boundaries of a figure. 
A surface is a perceptually regular region of space, whereas a boundary indicates an abrupt discontinuity in the surface, which marks off the shape (Cavanagh et al., 1990). The concepts of boundary and surface are thus closely intertwined, a fact that did not escape the early Gestalt psychologists: "The contour is not a separate entity, but rather determined by the nature of the figured surface to which it "belongs"” (Hartmann, 1935, p. 28). Modern theorizing suggests, however, that it is meaningful to discuss perceptual processes that are particular to the boundary or to the surface (e.g., Biederman, 1987; Gibson, 1966; Grossberg, 1987; Marr, 1982; Ullman, 1984). For instance, Grossberg (1987; Grossberg \& Mingolla, 1985; Grossberg \& Pessoa, 1998; Grossberg \& Todorović, 1988) has proposed a computational theory of figure-ground perception that comprises two distinct mechanisms: (1) a boundary contour module, which generates the edges and contours of the figures in a scene, and (2) a feature contour module, which governs a surface filling-in process, diffusing second-order attributes within the demarcated boundaries of the figure. Such dual systems are handy in modeling diverse figureground phenomena, including the illusory spreading of color into perceptually open areas (e.g., Nakayama, Shimojo, \& Ramachandran, 1990; Redies \& Spillmann, 1981; van Tuijl, 1975; Watanabe \& Sato, 1989), the suppression of perceived brightness in masked targets (Paradiso \& Nakayama, 1991), and the perceptual filling-in of scotomas originating either pathologically (Bender \& Teuber, 1946; Gassel \& Williams, 1963; Gerrits \& Timmerman, 1969; Lashley, 1941) or artificially (Ramachandran \& Gregory, 1991; Ramachandran, Gregory, \& Aiken, 1993).

\section{Privileged Status}

In principle, continuity in either luminance or chromaticity can be used to define a surface region, whereas discontinuity in either dimension can be used to define a boundary. Nevertheless, there has been some debate regarding the specific roles of luminance versus chromaticity information in surface versus boundary processing. The debate has several facets. One issue is whether boundaries and edges are privileged over surface gradients in figure and object recognition. Biederman and his colleagues (Biederman, 1987; Biederman \& Cooper, 1992; Fiser \& Biederman, 1995) have argued for the sufficiency of edge-based representations in recognizing objects (see also Ullman, 1984; Witkin \& Tenenbaum, 1983). In one study, Biederman and Ju (1988) showed that the speed and accuracy of observers' identifications were the same whether surface qualities were included in (i.e., color photographs) or excluded from (i.e., line drawings) the depictions of objects (see also Christou, Koenderink, \& van Doorn, 1996; Duncan \& Nimmo-Smith, 1996). ${ }^{1}$

Countering Biederman's position, however, is evidence that surface representations often supply unique figural information not available in edge-based representations (e.g., Humphrey, Goodale, Jakobson, \& Servos,
1994; A. Johnston, Hill, \& Carman, 1992; Tanaka \& Presnell, 1999; Yantis, 1995). Humphrey et al., for example, demonstrated that surface properties (e.g., color, fine texture) were more informative than outlined shape in recognizing objects, whether the observer was a visual form agnosic, drawn from a group of matched controls, or drawn from a group of perceptually unimpaired volunteers (see also Servos, Goodale, \& Humphrey, 1993). Moreover, marked effects of surface information on object identification have been observed both relatively early in processing, during visual segmentation (e.g., K. K. De Valois \& Switkes, 1983; Wurm, Legge, Isenberg, \& Luebker, 1993), and very late in processing, during visual recognition or naming (e.g., Ostergaard \& Davidoff, 1985; Price \& Humphreys, 1989). Nonetheless, the influence of surface properties may depend critically on several cognitive factors, including the color diagnosticity of the object (Tanaka \& Presnell, 1999) and the particular structural category from which the object is drawn (Price \& Humphreys, 1989). In the present study, we examined whether surface information, provided by continuity in either luminance or chromaticity, is sufficient for figural identification when boundary information has been fouled and whether its influence arises early or late in the processing of simple geometric patterns.

A second issue is whether luminance information enjoys special status over chromaticity information in identifying figures and objects. The debate emerges from physiological evidence indicating that scenes are decomposed by the visual system through a set of separate modules (Treisman, 1988), each specialized to analyze a different feature (e.g., color, motion) of the spatial array (Maunsell \& Newson, 1987; van Essen, 1985; van Essen, Maunsell, \& Bixby, 1981; Zeki, 1978, 1993). Theoretically, each module can represent the array's figureground relationships by a two-dimensional map of its featural values. Gregory $(1977,1979)$ proposed the existence of a master map representing spatial variation in luminance, to which all other featural maps, including the chromaticity map, must be aligned to ensure veridical perception. Empirical evidence in support of the primacy of luminance comes from studies showing impaired perception of figural boundaries at isoluminance, whether contours are real (Eskew \& Boynton, 1987) or illusory (Livingstone \& Hubel, 1987, 1988). Furthermore, chromatic discrimination is disrupted at isoluminance (Boynton, Hayhoe, \& MacLeod, 1977) and enhanced by luminance pedestals (Cole, Stromeyer, \& Kronauer, 1990), findings that suggest that chromatic processing is perceptually dependent on discontinuities in luminance.

Cavanagh $(1985,1987)$, among others (Mcllhagga \& Mullen, 1996; Ramachandran, 1992; Ware \& Cowan, $1983)$, has been critical of Gregory's $(1977,1979)$ position, arguing instead that two-dimensional figure-ground perception is accomplished as easily by color or textural differences as by luminance differences. In fact, in the natural world, chromatic changes may be more reliable markers of object shape, because luminance changes are 
also associated with shadow borders, which do not usually coincide with figural contours (Cavanagh \& Leclerc, 1989; K. K. DeValois \& Switkes, 1983). In the present study, we compared the ability of observers to identify two-dimensional patterns when figures were defined solely by luminance change with that when figures were defined solely by chromaticity change.

\section{Specialized Roles}

It has been suggested recently that luminance and chromaticity information may each enjoy specialized roles in figure-ground perception. Rogers-Ramachandran and Ramachandran (1998) uncovered psychophysical evidence of a fast-acting, luminance-based system used to extract figural contours from the visual array. These authors claimed that the system is rooted physiologically in the magnocellular pathway, which originates in the magnocellular layers of the lateral geniculate nucleus (LGN) and terminates in the parietal cortex (Livingstone \& Hubel, 1987, 1988; Ungerleider \& Mishkin, 1982; Zeki \& Shipp, 1988; for a review, see also Shapley, 1990). On this account, therefore, luminance information is processed specially by the magnocellularpathway for the purpose of detecting and identifying figural contours.

Rogers-Ramachandran and Ramachandran (1998) distinguished the contour-from-luminance system from a separate, slower system that uses chromatic information to extract the surface properties of the figure (see also Ramachandran, 1992; Ramachandran \& RogersRamachandran, 1991). This surface-from-chromaticity system may be associated physiologically with the parvocellular pathway, a wavelength-selective system implicated in form detection, which originates in the parvocellular layers of the LGN and terminates in the inferior temporal cortex (De Yoe \& van Essen, 1988). Whatever its precise physiological basis, the proposed second system implicates a specialized role for chromatic information for the purpose of detecting and identifying figural surfaces. ${ }^{2}$ The main goal of the present study was to evaluate the hypothesis that luminance information is processed specially for the extraction of figural boundaries and chromatic information is processed specially for the extraction of figural surfaces.

\section{The Present Study}

In each of three experiments, pattern identification was assessed by asking participants to judge whether a near-threshold test figure was the same or different in shape to a high-contrast comparison figure. The figural dimension was defined as the first-order dimensioneither luminance or chromaticity - along which each test figure differed from its ground within a block of trials. In the luminance tasks, the figural dimension was luminance; in the chromaticity tasks, the figural dimension was chromaticity. In each experiment, each task was performed under several conditions, to evaluate the effects on pattern identification of degrading a figure's boundary or its surface. In the baseline conditions, the test stimulus was intact. In the contour degradation conditions, the boundary of the figure was degraded along the figural dimension. In the surface degradation conditions, the region of the figure was degraded along the figural dimension.

This setup enabled us to address three issues. First, each participant was pretested to equate his or her baseline performance levels between the two figural dimensions. In other words, stimulus values of luminance and chromaticity were selected individually so that each participant's identification performance in the baseline condition was approximately the same in the luminance tasks as in the chromaticity tasks. This procedure ensured that the information on pattern identification contributed by the luminance dimension was comparable with the information contributed by the chromaticity dimension. This approach guaranteed the sufficiency of both luminance and chromaticity for figure-ground segregation. More important, the procedure established the baseline condition as a standard of performance with which to compare performance in the various degradation conditions.

Second, by separately degrading the surface or the boundary of the figure, we were able to determine whether surface and boundary features provide equivalent figural information or whether one of these two figural characteristics is relatively more fundamental to pattern identification. In particular, by comparing performance in the contour degradation conditions with baseline, we could evaluate whether surface qualities are sufficient for adequate figure-ground perception when boundary qualities have been marred.

Finally, by subjecting each figural dimension to each degradation condition separately, we were able to determine whether the two types of degradation act selectively on the two dimensions. More exactly, we were interested in whether identification performance in the luminance tasks was relatively worse when the contour was degraded than when the surface was degraded or when the figure was intact. This result would suggest that luminance information had a specialized function in the processing of the figural boundaries. We were also interested in whether performance in the chromaticity tasks was relatively worse when the surface was degraded than when the contour was degraded or when the figure was intact. This result would suggest that chromaticity information had a specialized role in the processing of the figural surfaces. Evidence against specialized dimensional function would obtain if performance to a particular figural dimension (luminance or chromaticity) was disrupted equivalently (or not at all) by the two types of degradation.

\section{EXPERIMENT 1}

The degradation procedures used in Experiment 1 are portrayed in Figure 1. On each trial of each condition, one of five two-dimensional shapes served as the test 


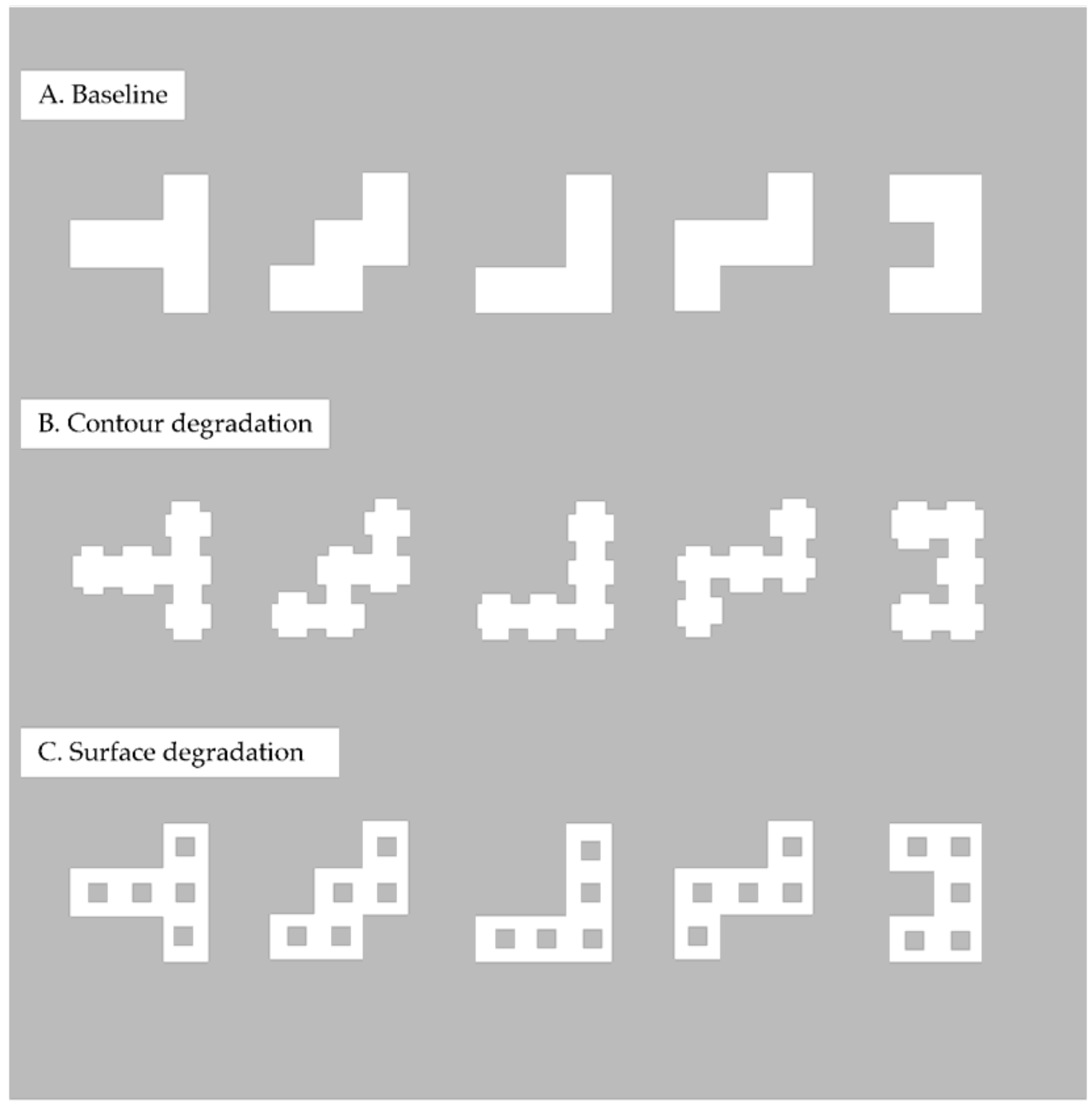

Figure 1. Five two-dimensional shapes that served as the test stimuli in the present study. Each stimulus belongs to a rotation/reflection subset of three, using Garner's (1974) criteria. Panel A contains the intact stimuli used as comparison stimuli and as test stimuli in the baseline condition. Panel $B$ contains the corresponding figures used as test stimuli in the contour degradation condition. Panel $C$ contains the test stimuli used in the surface degradation condition. The total area of degradation is equal in panels $B$ and $C$.

stimulus. The stimuli were selected to be comparable in figural goodness, defined according to Garner's (1974) criteria: A total of three other patterns could be created from $90^{\circ}$ rotation and/or reflection of any pattern in Figure 1. Test stimuli were intact in the baseline condition, depicted in the top row of Figure 1. To degrade these figures, square regions along either the figure's contour (contour degradation, depicted in the middle row) or its surface (surface degradation, depicted in the bottom row) were equated to the ground in both luminance and chromaticity. The total area of degradation was equal in the two degradation conditions. As one can see, although the addition of degrading squares blemished the figures, the overall appearance of each degraded figure could be matched easily to its intact counterpart.
Figure 2 depicts the stimulus display on a typical trial. The near-threshold test stimulus appeared within a green background window that was superimposed on a black screen. An intact comparison stimulus appeared in high contrast on the black screen. The observers' task in each condition was to judge whether the test stimulus was the same as or different from the comparison stimulus in overall shape.

The degradation procedures altered the spatial frequency components of the test stimuli. In particular, surface degradation created higher spatial frequencies as compared with either contour degradation or baseline. An example of the effects of degradation on the twodimensional spatial frequencies of one test stimulus appears in Figure 3. Unfortunately, these differences in spa- 


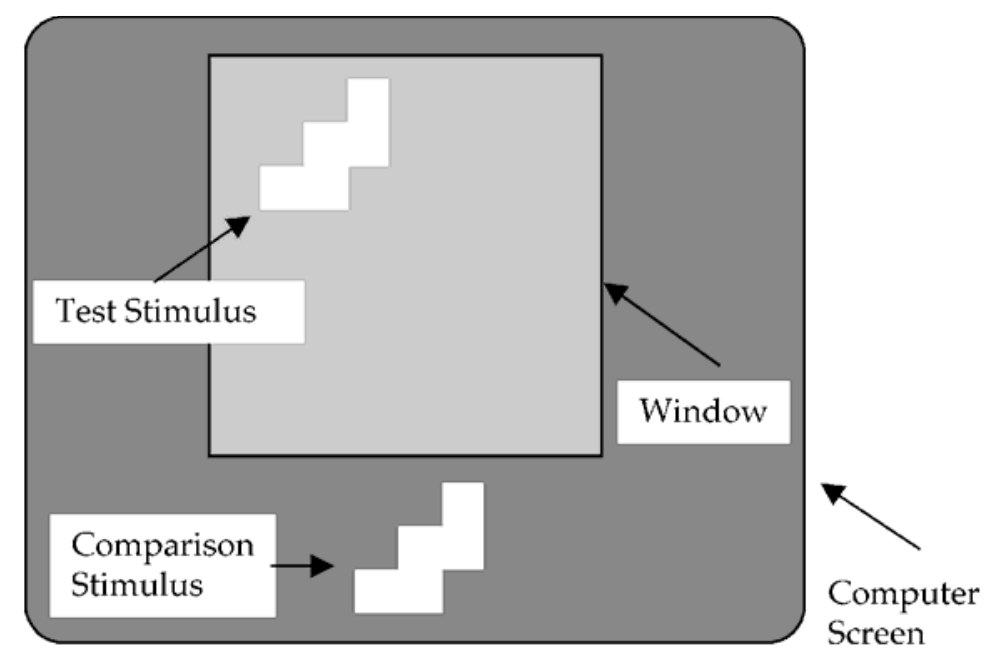

Figure 2. The computer display on a typical trial in Experiments 1 and 2. A near-threshold test stimulus appeared within a green background window that was superimposed on a black computer screen. An intact comparison stimulus appeared in high contrast below the background window. An observer judged whether the test stimulus was the same as or different from the comparison stimulus in overall shape.

tial frequency components across conditions might underlie any observed effects of surface degradation versus boundary degradation. Moreover, spatial frequency has different effects on luminance contrast sensitivity versus chromaticity contrast sensitivity, further complicating our tests of dimensional selectivity.

The typical contrast sensitivity function (CSF) for luminance in humans shows peak sensitivity between 2 and $6 \mathrm{c} / \mathrm{deg}$, with a sharp loss of sensitivity over higher spatial frequencies and a more moderate but still pronounced loss of sensitivity over lower spatial frequencies (Campbell \& Robson, 1968; R. L. De Valois, Morgan, \& Snodderly, 1974). Contrarily, the CSF for chromatic patterns shows a sharp loss in sensitivity for frequencies greater than $3 \mathrm{c} / \mathrm{deg}$ but little attenuation at lower spatial frequencies (Granger \& Heurtley, 1973). On the basis of these differences in CSFs, one might expect to find evidence consistent with dimensional selectivity arising solely from the different spatial frequency compositions between degradation conditions. For instance, performance in the chromaticity tasks might be especially undermined by surface degradation, owing simply to poorer sensitivity to the relatively higher spatial frequencies in this condition. Such an interpretation could compromise any conclusion that luminance and chromaticity have specialized roles in figure-ground perception.

To examine the effects of spatial frequency on performance in this paradigm, Experiment 1 was conducted in two separate ranges of spatial frequency. In Experiment $1 \mathrm{~A}$, the participants viewed the stimulus displays from a distance of $55 \mathrm{~cm}$; consequently, the spatial frequencies of the test stimuli fell below a Nyquist rate (R. L. De Valois \& K. K. De Valois, 1988) of 13 c/deg. In Ex- periment $1 \mathrm{~B}$, the same participants viewed the stimulus displays from a distance of $75 \mathrm{~cm}$; consequently, the spatial frequencies of the test stimuli fell below a relatively higher Nyquist rate of $17.8 \mathrm{c} / \mathrm{deg}$. The scale axes in Figure 3 depict these two spatial frequency ranges. In the case of surface degradation, the longer viewing distance of Experiment 1B pushed the highest spatial frequencies in the image profiles beyond the $3 \mathrm{c} / \mathrm{deg}$ limit characterizing asymptotic contrast sensitivity of chromatic patterns (see Mullen, 1985). By comparing performance across Experiments $1 \mathrm{~A}$ and $1 \mathrm{~B}$, therefore, we were able to determine the relative influence of spatial frequency on the interfering effects of degradation within each task.

\section{Method}

Participants. Three observers, 2 paid participants (H.W. and F.H.) recruited from the Purdue University community and the first author (N.Y.), participated in both experiments. The rate was $\$ 6$ per hour. All the observers had normal color vision, as tested by Ishihara color plates, and normal or corrected visual acuity. This investigation was approved by the Human Subjects Committee at Purdue University. The nature of the procedures was explained fully, and informed consent was obtained from each participant.

Apparatus. All the stimuli were shown on an AppleColor 13-in. viewable diagonal high resolution $\mathrm{RGB}$ monitor $(640 \times 480$ pixels, $66.7 \mathrm{~Hz}, 256$ intensity levels per color) and were generated by a Macintosh IIci microcomputer, which permits 256 simultaneously displayable colors or luminance levels. Internal look-up tables in the Macintosh were used to linearize the luminance output of each phosphor independently. Only the red and green guns of the monitor were used. The CIE chromaticity coordinates $(x, y)$ of the two guns were $0.625,0.340$ (red) and $0.280,0.595$ (green). The experiments were conducted in a darkened IAC sound-attenuating chamber.

Stimuli. On each trial, a green color background window (ground), subtending $4.6^{\circ} \times 4.6^{\circ}$ of visual angle in Experiment $1 \mathrm{~A}$ and $3.4^{\circ} \times 3.4^{\circ}$ of visual angle in Experiment $1 \mathrm{~B}$, appeared in the 
A. Baseline

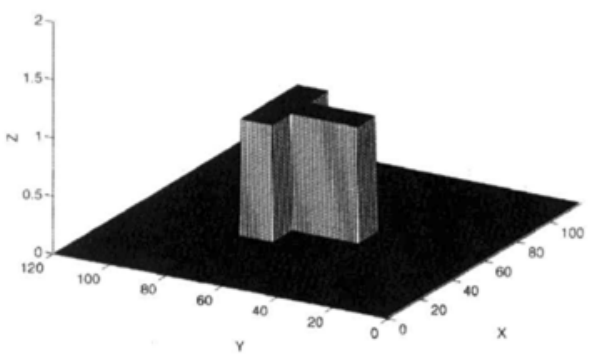

\section{B. Contour Degradation}

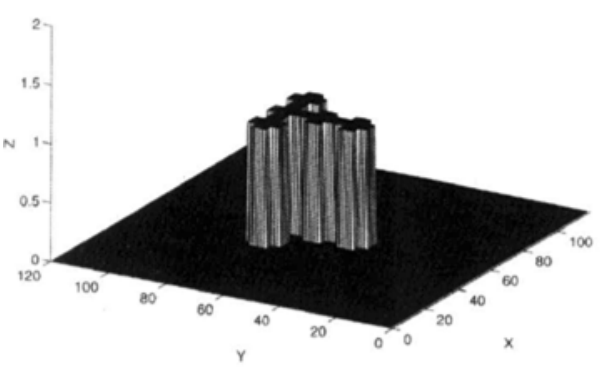

C. Surface Degradation

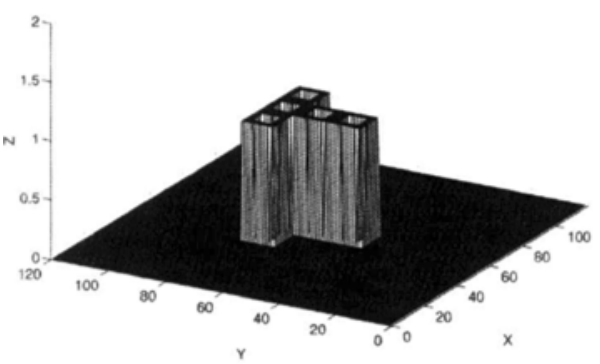

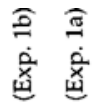
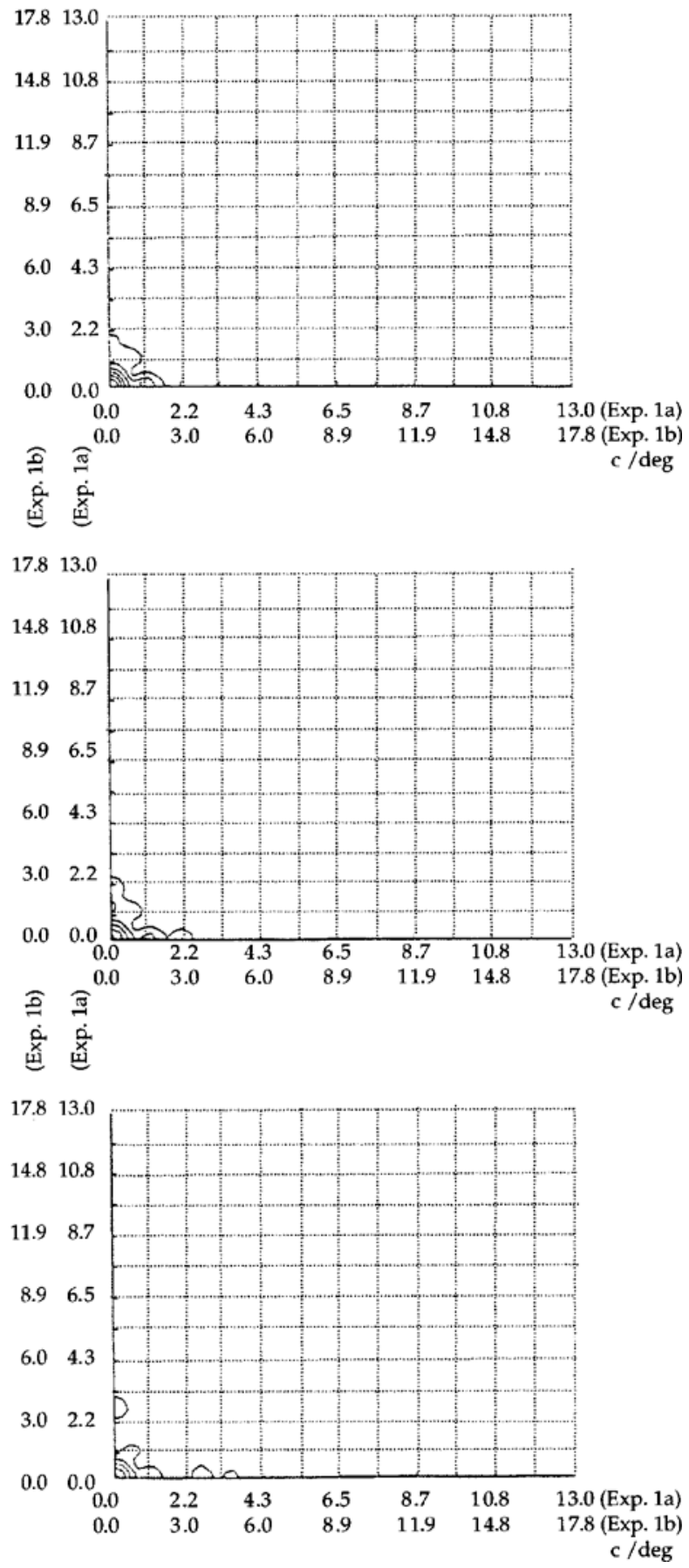

Figure 3. A three-dimensional representation and Fourier-transform contour plot of one test stimulus in each of the three conditions of Experiments 1A and 1B: baseline (panel A), contour degradation (panel B), and surface degradation (panel C). The scale axes distinguish the two spatial frequency ranges in Experiment $1 \mathrm{~A}(\mathrm{Nyquist} \mathbf{r a t e}=13 \mathrm{c} / \mathrm{deg})$ and Experiment $1 \mathrm{~B}$ (Nyquist rate $=\mathbf{1 7 . 8} \mathrm{c} / \mathrm{deg}$ ). Notice that surface degradation created higher spatial frequencies, as compared with either contour degradation or baseline. 


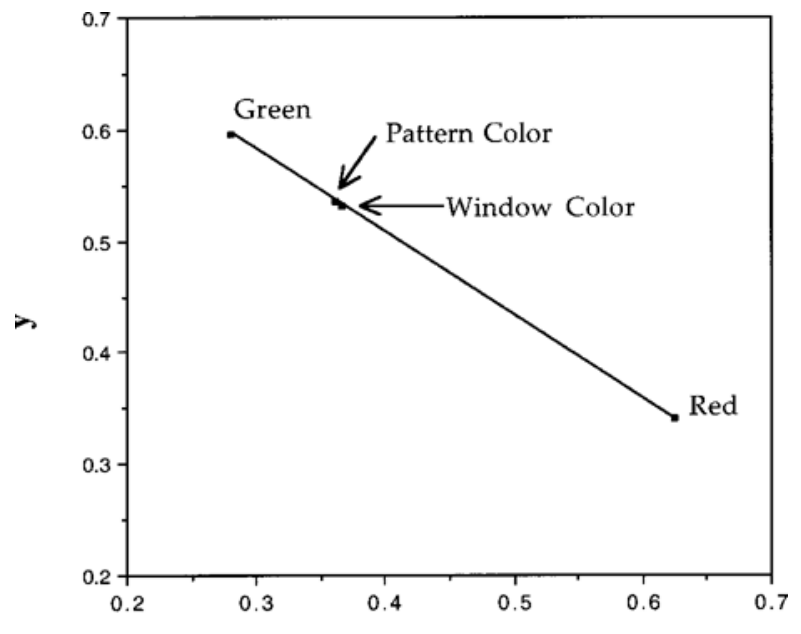

$\mathbf{x}$

Figure 4. The CIE chromaticity coordinates $(x, y)$ of test and comparison stimuli in Experiments $1 \mathrm{~A}$ and 1B. The points labeled "red" and "green" represent the chromaticity coordinates of the color monitor's red and green phosphors, respectively. The point labeled "window color" represents the chromaticity coordinates of the background window within which test stimuli appeared. Because only the red and green guns of the monitor were used, all stimulus colors fall along a line connecting the points "red" and "green." In chromaticity tasks, the color of a test stimulus was greener than the window color. The point labeled "pattern color" depicts an example of CIE values used for observer N.Y.

center of a black computer screen (see Figure 2). The CIE chromaticity coordinates of the ground were $0.366,0.531$; its luminance was $33.5 \mathrm{~cd} / \mathrm{m}^{2}$, calibrated on a Gossen MOVA-MONITOR digital luminance meter. The luminance of the black screen display was $1.3 \mathrm{~cd} / \mathrm{m}^{2}$. On each trial, a test pattern appeared in the background window, and a comparison pattern appeared on the black screen, $2.8^{\circ}$ (Experiment $1 \mathrm{~A}$ ) or $2.0^{\circ}$ (Experiment $1 \mathrm{~B}$ ) below the center of the window (see Figure 2). The test and comparison stimuli were identical in CIE chromaticity coordinates and in luminance values. Stimuli were selected from the 15 patterns in Figure 1, subtending approximately $1.4^{\circ} \times 1.4^{\circ}$ of visual angle in Experiment $1 \mathrm{~A}$ and $1.0^{\circ} \times 1.0^{\circ}$ of visual angle in Experiment $1 \mathrm{~B}$. Orientation was held constant. Comparison stimuli were always presented intact (top row of Figure 1).

Identif ication performance was tested in each of three conditions. On half of the trials of each condition, the comparison stimulus matched in shape an intact version of the test stimulus (same trials), and on half of the trials, the two stimuli mismatched in shape (different trials). In the baseline condition, the test stimulus on each trial was selected at random from the five stimuli in the top row of Figure 1. The area of each pattern was identical $\left(0.98 \mathrm{~cm}^{2}\right)$. In the degradation conditions, square regions effectively eliminated one fourth $\left(0.24 \mathrm{~cm}^{2}\right)$ of the area of the intact pattern. The square regions were equal in luminance and chromaticity to the ground. In the contour degradation condition, the test stimulus on each trial was selected at random from the five stimuli in the middle row of Figure 1 ; in the surface degradation condition, the test stimulus was drawn from the five stimuli in the bottom row of Figure 1.

A test stimulus differed from its ground only in luminance in the luminance tasks and only in chromaticity in the chromaticity tasks. Each task was performed under each of the three conditions. Preliminary tests of identification prior to the experiments were con- ducted using the baseline condition to choose stimulus values along each figural dimension for each observer. The goal of these pretests was to establish a baseline sensitivity $\left(d_{\mathrm{a}}\right)$ of approximately 2.0 (accuracy of approximately $85 \%-90 \%$ ). At this sensitivity level, the subjective impression of the test stimulus in the window was that it was difficult to see but detectable. In the luminance tasks, the test pattern was brighter than the ground but equal in CIE chromaticity coordinates; luminance of test patterns in these tasks was $34.6 \mathrm{~cd} / \mathrm{m}^{2}$ for all 3 observers, as selected by a pretest performed prior to each experiment. In the chromaticity tasks, the test pattern was isoluminant to the ground but greener than the ground's color, as is represented in Figure 4; the CIE chromaticity coordinates of test patterns in this task, determined by pretest prior to each experiment, were 0.361 and 0.535 (observer N.Y., both experiments), 0.360 and 0.536 (observer H.W., both experiments), 0.357 and 0.538 (observer F.H., Experiment 1A), and 0.360 and 0.536 (observer F.H., Experiment $1 \mathrm{~B}$ ). Isoluminance in the chromaticity tasks was measured for each observer individually by heterochromatic flicker photometry (see Buser \& Imbert, 1992; Enns \& Rensink, 1991); two colors differing in dominant wavelength appeared alternately over the entire screen at a frequency of $30 \mathrm{~Hz}$. Each observer adjusted the luminance of one color until the flicker rate was at a perceptual minimum.

Procedure. A rating scale method was used to obtain figural identification judgments. On each trial, an observer was asked to determine whether the intact form of the test pattern in the window was identical to that of the comparison pattern below the window. When a test pattern was degraded in contour or surface, the observer was asked to use the general outline of the pattern to determine its shape. No observer had difficulty understanding the instructions. The observer responded by clicking with a mouse on one of six screen rating buttons, labeled "definitely same," "probably same," "possibly same," "possibly different," "probably different," and "definitely different."

On each trial, the test pattern appeared randomly in one of 25 positions within the background window; pilot testing indicated that positional uncertainty fostered the use of global (rather than partial) figural characteristics in observers' identifications. The observer viewed the display binocularly from a distance of either $55 \mathrm{~cm}$ (Experiment 1A) or $75 \mathrm{~cm}$ (Experiment 1B), with the head immobilized in a chinrest. To control for differences in information accumulation across trials and experiments, the display appeared for $2 \mathrm{sec}$, and a 5 -sec deadline was imposed on the rating response. Pilot data indicated that the observers could respond within this deadline on over $99 \%$ of the trials across all the conditions. Auditory feedback was provided on error trials and on trials in which response time exceeded $5 \mathrm{sec}$. Trials involving delayed response times were repeated at the end of the block. Accuracy was summarized for the observer after the last trial in each block. Ratings were saved automatically to a data file.

Experiment 1B followed Experiment 1A by several weeks. The two experiments were conducted identically: After pretesting, each observer began a series of 10 sessions, including 5 sessions of luminance tasks and 5 sessions of chromaticity tasks, tasks alternating between sessions. Each session was preceded by $2-3$ min of adaptation to the darkened chamber. The first session for each type of task was treated as practice, and the data were excluded from analysis. Each session comprised four blocks of trials, including one block of 32 practice trials and three blocks of 160 experimental trials, one for each of the three conditions (i.e., baseline, contour degradation, and surface degradation). The order of the three conditions within a session was random. Practice data were discarded. Each session lasted approximately $50 \mathrm{~min}$.

\section{Results}

The rating data were analyzed using signal detection theoretics (Green \& Swets, 1966; McNicol, 1972) to estimate best-fitting receiver operating characteristic (ROC) 
curves for each of the 3 observers individually. The sensitivity index was $d_{\mathrm{a}}$, the distance between the means of the signal and noise distributions, measured in units of root-mean square standard deviation (see Macmillan \& Creelman, 1991; Swets \& Pickett, 1982). To obtain $d_{\mathrm{a}}$, the slope and intercept of each ROC curve were derived from maximum-likelihood estimation procedures (Dorfman \& Alf, 1969).

Average sensitivity (across four sessions) for each observer in each condition is summarized in Figure 5 (luminance tasks) and Figure 6 (chromaticity tasks); results of Experiment 1A appear in the left panels, Experiment 1B in the right panels. An analysis of variance (ANOVA) was performed on sensitivity difference scores $\left(\Delta d_{\mathrm{a}}\right)$, with $d_{\mathrm{a}}$ in the baseline condition subtracted from $d_{\mathrm{a}}$ in each of the degradation conditions. A negative difference score thus reflected performance loss in a degradation condition relative to baseline. The independent variables were degradation (two levels: contour and surface), task (two levels: luminance and chromaticity), and experiment (two levels: 1A and 1B); session served as the error term. All the main effects and interactions reported as significant were reliable for each participant individually and after Greenhouse-Geisser (1959) correction.

The only factor to yield a significant main effect was task $\left[F(1,3)=373.35, M S_{\mathrm{e}}=0.01, p<.001\right]$. Greater overall loss was observed in the chromaticity tasks $\left(\Delta d_{\mathrm{a}}=\right.$ $-0.86)$ than in the luminance tasks $\left(\Delta d_{\mathrm{a}}=-0.37\right)$. In evaluating the hypothesis of specialized dimensional function, the critical effect is found in the interaction between degradation and task. This interaction, depicted in Figure 7 , was highly significant $\left[F(1,3)=178.77, M S_{\mathrm{e}}=\right.$ $0.02, p<.001]$. As one can see, figural identification in the luminance tasks was disrupted by contour degradation, but not by surface degradation. On the other hand, figural identification in the chromaticity tasks was disrupted by both forms of degradation; however, surface degradation was twice as harmful to performance in these tasks as contour degradation. This interactive pattern was observed in both Experiment 1 A and Experiment 1B. Nonetheless, there was a significant three-way interaction among degradation, task, and experiment $[F(1,3)=$ 23.09, $\left.M S_{\mathrm{e}}=0.01, p<.05\right]$. The three-way interaction appeared because the increased viewing distance (and higher average spatial frequencies) in Experiment 1B caused additional performance loss when surfaces were degraded in luminance tasks (Experiment 1A, $\Delta d_{\mathrm{a}}=0.16$; Experiment $\left.1 \mathrm{~B}, \Delta d_{\mathrm{a}}=-0.19\right)$ and when contours were degraded in the chromaticity tasks (Experiment 1A, $\Delta d_{\mathrm{a}}=$ -0.44 ; Experiment 1B, $\left.\Delta d_{\mathrm{a}}=-0.69\right)$. Loss was equivalent across experiments in the other conditions. Moreover, there were no two-way interactions involving experiment.

\section{Discussion}

The results of Experiment 1 provide psychophysical evidence for specialized dimensional roles in figureground perception. Degradation of contours selectively harmed identification of figures defined by luminance, whereas degradation of surfaces selectively harmed identification of figures defined by chromaticity. This pattern of results is consistent with a dual-mechanism system in which luminance information is processed for the extraction of figural boundaries and chromaticity information is processed for the extraction of figural surfaces (e.g., Rogers-Ramachandran \& Ramachandran, 1998).

Despite tentative support for the hypothesis of specialized function, several results suggest that dimensional selectivity was not complete, with both the boundary and the surface mechanisms evincing some information seepage past their supposedly specialized gates. Most telling was the form of interaction observed between the figural dimension (task) and the type of degradation. Degrading a figure's surface did little harm to the identification of figures defined by luminance. In fact, at least one observer (F.H.) displayed enhanced sensitivity in this condition, relative to baseline. The result fits well with the hypothesis that luminance information is largely ignored by a surface extraction mechanism. Degrading a figure's boundary, however, was quite detrimental to the identification of figures defined by chromaticity. Chromaticity information would therefore appear to enter, together with luminance information, into the boundary extraction mechanism to derive shape from contour (see McIlhagga \& Mullen, 1996). The results further suggest that, when viewing a figure separated from its ground only by chromaticity, perceivers achieve segregation by relying jointly on the figure's surface and its boundary. Indeed, the main effect of task can be explained by the hypothesis that chromaticity contributes to both surface and boundary representations, whereas luminance contributes mainly to boundary representations (but see Experiment 3 ).

The three-way interaction of degradation and task with experiment provides evidence that surface extraction is not entirely selective to chromatic information. A partial influence of luminance on surface perception was apparent through the modulation of spatial frequency. At lower spatial frequencies, established through a relatively short viewing distance, the degradation of the figure's surface had little effect on the average identification accuracy of figures defined by luminance. At higher spatial frequencies (farther viewing distance), however, each of the 3 participants suffered comparatively greater loss (or lesser gain) as they performed this condition. This result may reflect the normally greater reliance of the surface extraction mechanism on luminance information as spatial frequency approaches the region of steep fall-off in chromatic contrast sensitivity. Whatever the cause, the result implies that, at least under certain conditions, luminance information may have a palpable role in the processing of figural surfaces. More generally, the results of Experiment 1 indicate that the specialized processing of contours from luminance and surfaces from chromaticity is real but may reflect a processing preference more than an information-tight pathway. 
Experiment 1a

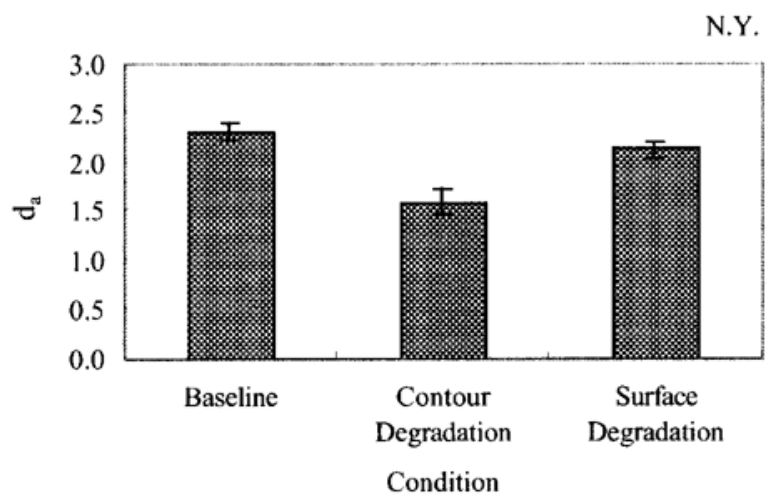

H.W.

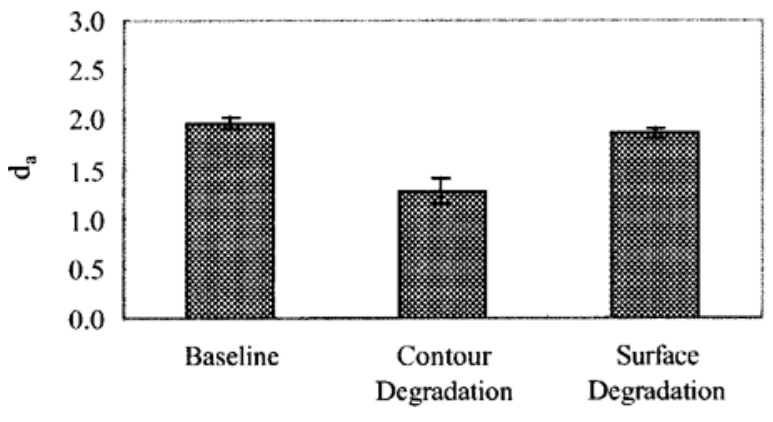

Condition

F.H.

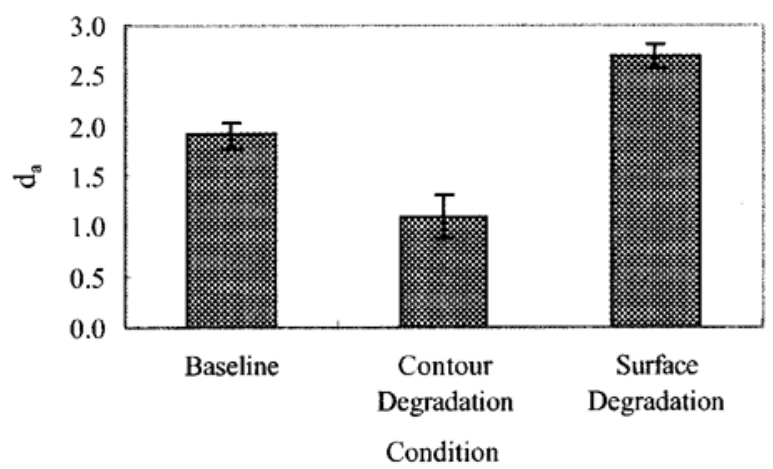

Experiment $1 \mathrm{~b}$

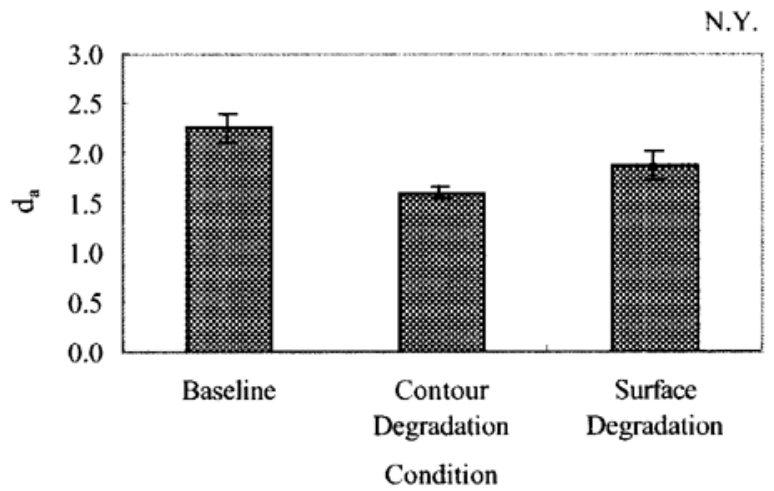

H.W.

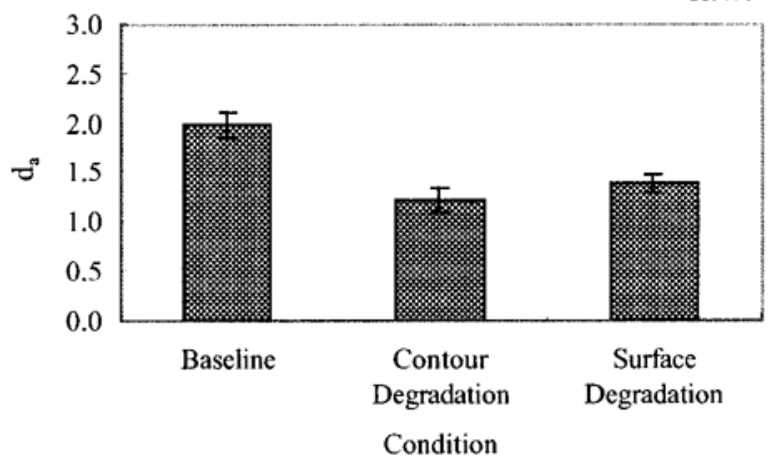

F.H.

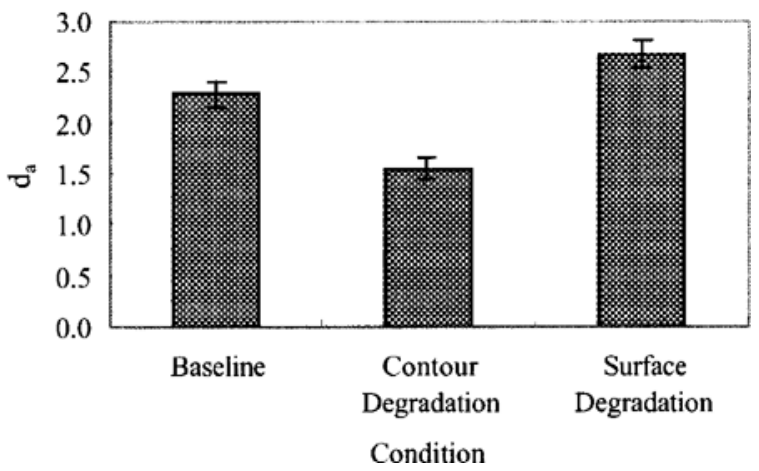

Figure 5. Average sensitivity $\left(d_{\mathrm{a}}\right)$ in luminance tasks for each of 3 observers (N.Y., H.W., and F.H.) in each of three conditions (baseline, contour degradation, and surface degradation) in Experiments $1 \mathrm{~A}$ (left panels) and $1 \mathrm{~B}$ (right panels). When surfaces were degraded, the observers experienced greater performance loss (relative to baseline) in Experiment $1 \mathrm{~B}\left(\Delta d_{\mathrm{a}}=-0.19\right)$ than in Experiment $1 \mathrm{~A}\left(\Delta d_{\mathrm{a}}=0.16\right)$.

\section{EXPERIMENT 2}

In Experiment 1, we degraded surfaces and boundaries by contamination: Spots of ground color were speckled abruptly along the contour or through the center of the figures. Although contamination makes it more difficult to follow a contour or surface visually, it does not target directly the physical basis of surfaces or boundaries. Sur- faces are defined by continuity, whereas boundaries are defined by discontinuity. A more direct approach to degradation might involve creation of a gradual (or severe) discontinuity in the surface or a gradual continuity in the boundary. In Experiment 2, we took this approach by blurring the boundaries and sharpening the surface irregularities of the figures but otherwise adopting the identification procedure of Experiment 1. In this way, we could 


\section{Experiment la}
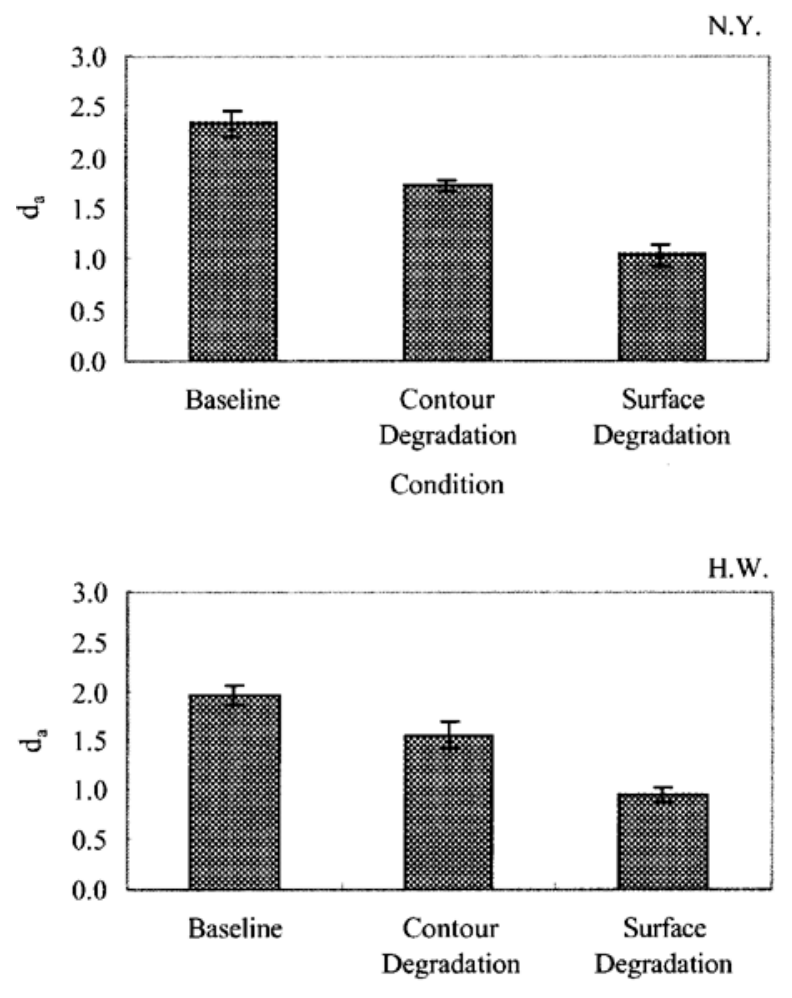

Condition

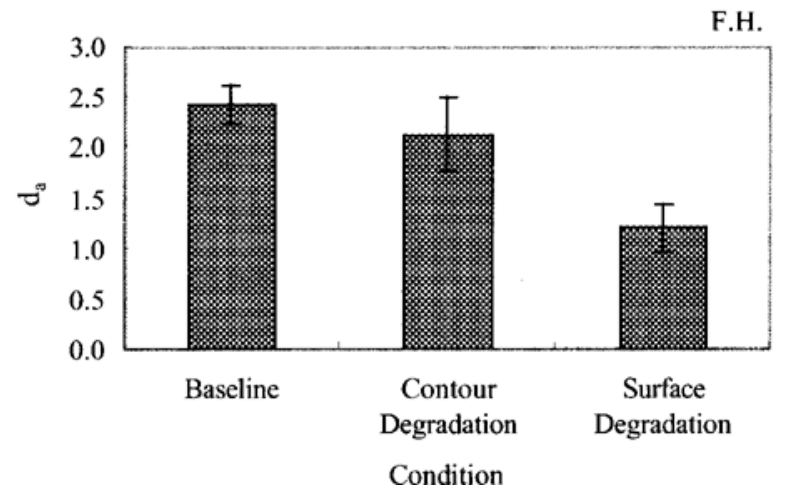

\section{Experiment $1 \mathrm{~b}$}
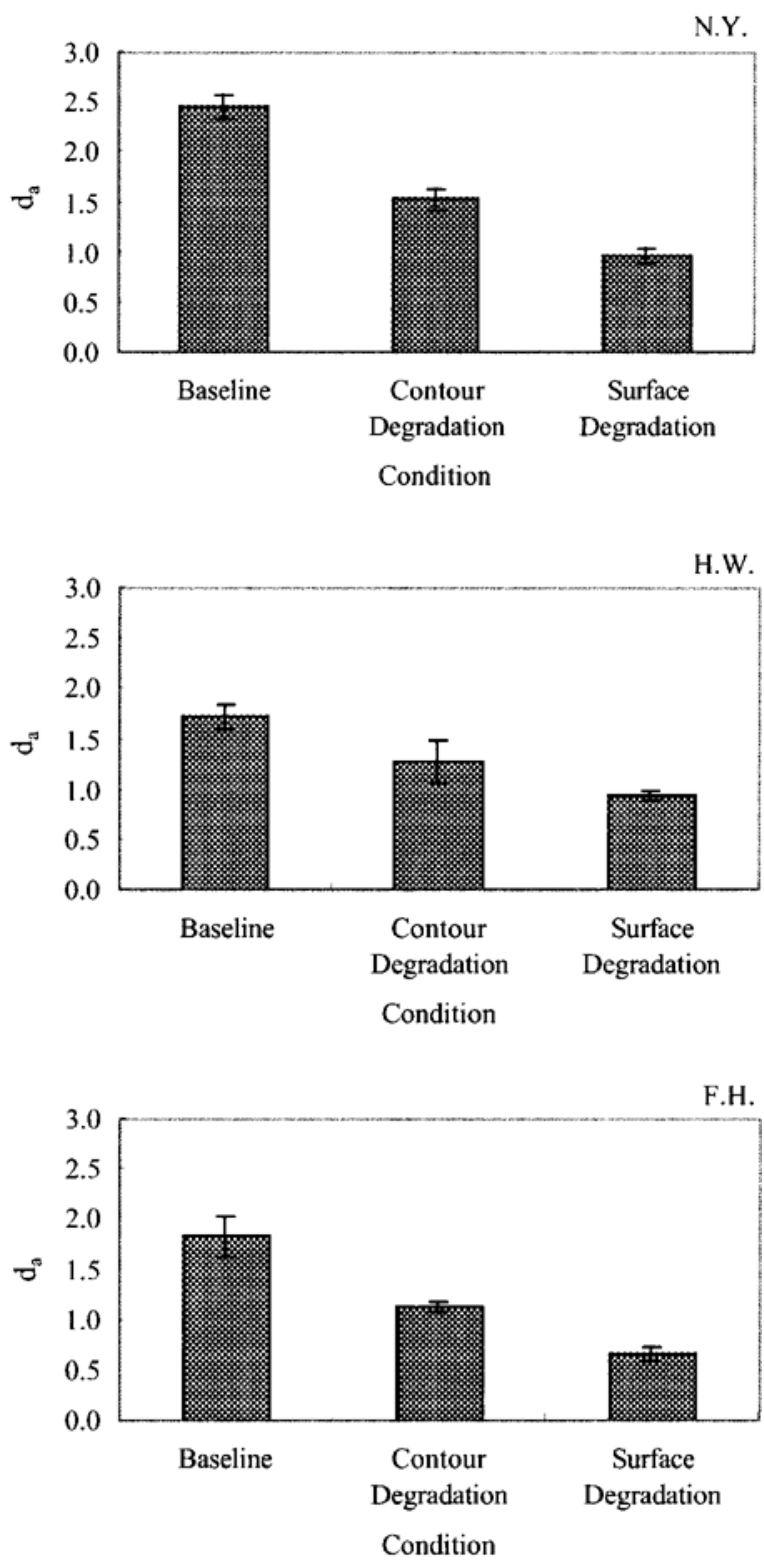

Figure 6. Average sensitivity $\left(d_{\mathrm{a}}\right)$ in the chromaticity tasks for each of 3 observers (N.Y., H.W., and F.H.) in each of three conditions (baseline, contour degradation, and surface degradation) in Experiments $1 \mathrm{~A}$ (left panels) and 1B (right panels). When contours were degraded, the observers experienced greater performance loss (relative to baseline) in Experiment $1 B\left(\Delta d_{\mathrm{a}}=-0.69\right)$ than in Experiment $1 \mathrm{~A}\left(\Delta d_{\mathrm{a}}=-\mathbf{0 . 4 4}\right)$.

subject the hypothesis of specialized dimensional function to a new test, while maintaining our ability to compare the new results with those obtained in Experiment 1.

As in Experiment 1, the boundaries of intact figures in the baseline condition of Experiment 2 were created by an abrupt change in luminance or chromaticity between the surface and the ground. This condition is represented in panel A of Figure 8. To blur the figural boundaries, we ramped the discontinuity between the figural surface and the ground, using a technique similar to that applied by Cornsweet (1970). As is shown in panel B, two intermediate values of luminance (in luminance tasks) or chromaticity (in chromaticity tasks) were selected between the ground value and the surface value. These intermediate values then served as pixel-sized steps along the entire contour to create a gradual transition at the boundary be- 


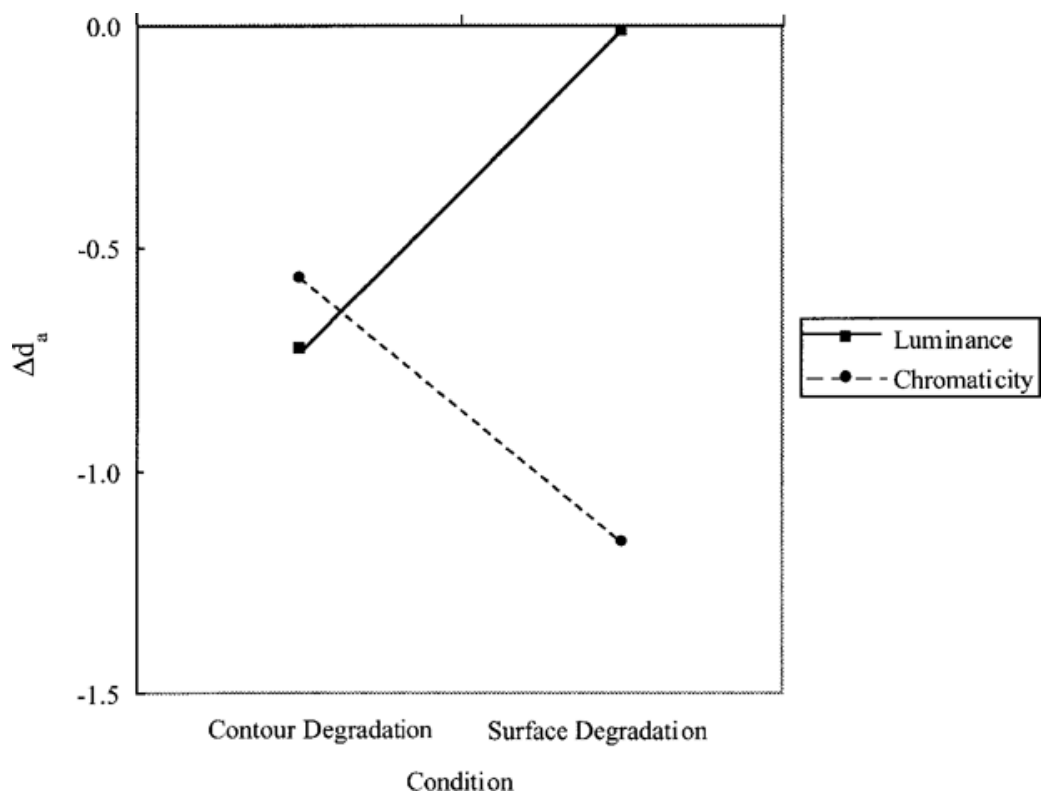

Figure 7. Average difference in sensitivity from baseline $\left(\Delta d_{\mathrm{a}}\right)$ in luminance and chromaticity tasks under contour-degradation and surface-degradation conditions across Experiments $1 \mathrm{~A}$ and $1 \mathrm{~B}$. Note the crossover interaction between degradation and task: Performance in the luminance tasks was most disrupted by contour degradation, whereas performance in the chromaticity tasks was most disrupted by surface degradation.

tween surface and ground. Because the differences in luminance or chromaticity between the surface and the ground were near threshold for each participant, the intermediate steps were below threshold. Nonetheless, the ramping technique effectively blurred the figural boundary; it thus served as the contour degradation in Experiment 2 . We asked whether this type of contour degradation was more disruptive to identification performance when the figure was defined by luminance than when it was defined by chromaticity.

As in Experiment 1, the surfaces of intact figures in the baseline condition of Experiment 2 were created by a constant level of luminance or chromaticity within the figure's boundary (see Figure 8A). To disrupt the figural surfaces, we introduced discontinuity within the figure. We tested two types of surface degradation in Experiment 2 by manipulating two degrees of surface irregularity. Gradient surface degradation was created by reducing the luminance or chromaticity from the boundary by two pixel-sized steps within the figure. The technique, which is depicted in panel $\mathrm{C}$ of Figure 8, is analogous to the technique of contour degradation but creates a surface gradient that may be similar to chromatic or luminance (shadow) gradients visible on everyday objects (Cavanagh \& Leclerc, 1989). To produce more severe discontinuity, sharp surface degradation was created by steeply shifting the luminance or chromaticity of the interior of the figure to the ground value. The latter technique is depicted in panel D of Figure 8. Although the gradient and sharp surface degradations differed in the degree of surface discontinuity, we expected both types to disrupt processing of surface properties. We asked whether these types of surface degradation were more disruptive of identification performance when the figure was defined by chromaticity than when it was defined by luminance.

\section{Method}

Participants. The 3 observers tested in Experiment 1 participated. The 2 nonauthor participants were paid at a rate of $\$ 6$ per hour.

Apparatus, Stimuli, and Procedure. The apparatus and display characteristics - test stimuli within a green background window superimposed on a black computer screen (see Figure 2) were identical to those in Experiment 1. The viewing distance was $55 \mathrm{~cm}$, as in Experiment 1A. Near-threshold differences in luminance and chromaticity were identified for each participant by baseline pretesting, as in Experiment 1. Two additional values of luminance and chromaticity, falling equidistant between nearthreshold and ground, were identif ied individually for each participant to create three personalized isophysical steps. Isoluminance of chromaticity values was determined by heterochromatic flicker photometry. The near-threshold and step values for each participant are summarized in Table 1.

The luminance and chromaticity values were used to create a baseline condition and three degradation conditions. The baseline condition was identical to Experiment 1, with each of five possible intact patterns differing from the ground in either the near-threshold luminance value (in luminance tasks) or the near-threshold chromaticity value (in chromaticity tasks); the intact pattern subtended approximately $1.4^{\circ} \times 1.4^{\circ}$ of visual angle (see Figure $8 \mathrm{~A}$ ). In the contour degradation condition, the intermediate values of lumi- 
A. Baseline

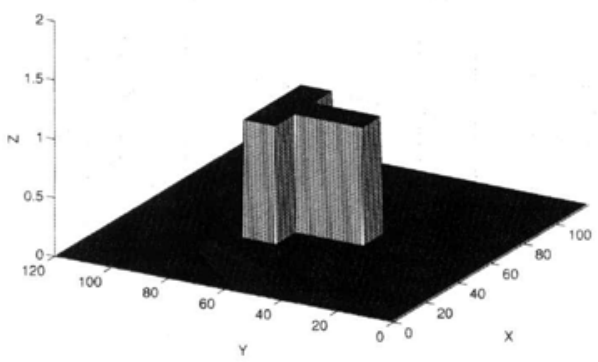

B. Contour Degradation

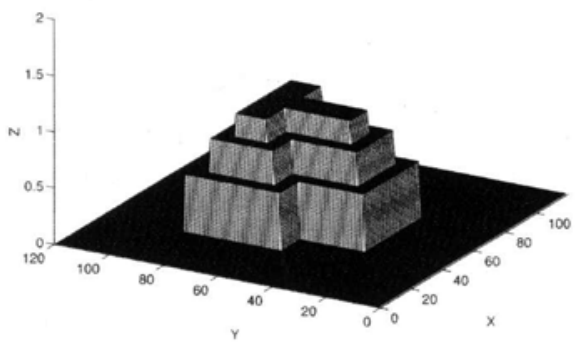

C. Gradient-surface Degradation

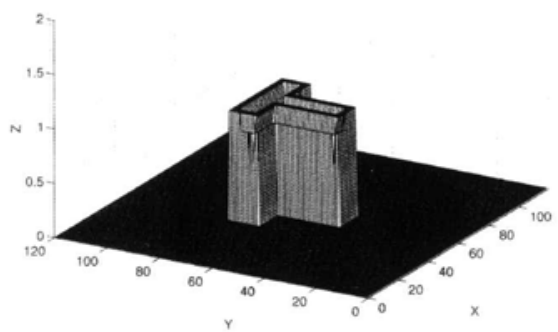

D. Sharp-surface Degradation

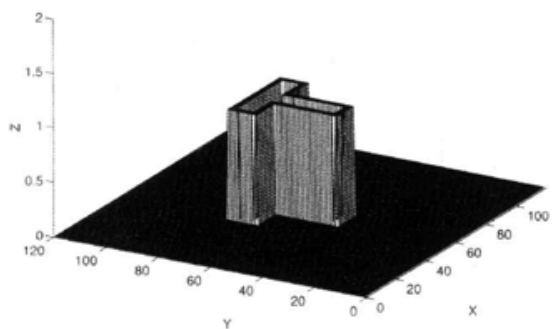

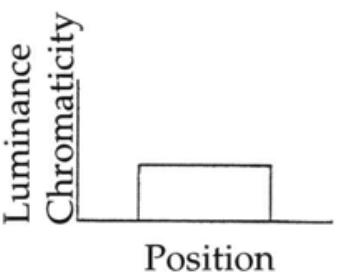
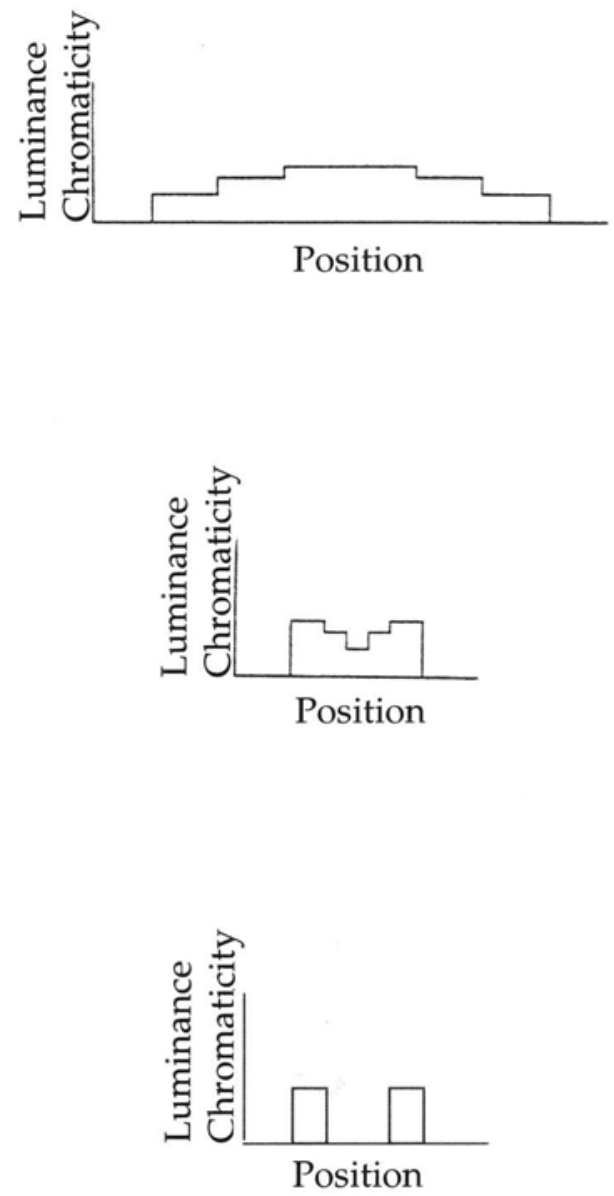

Figure 8. Luminance (or chromaticity) profiles for one stimulus within each of the conditions of Experiment 2: baseline (panel A), contour degradation (panel B), gradient surface degradation (panel C), and sharp surface degradation (panel D). To create contour degradation, two intermediate (subthreshold) values of luminance (or chromaticity) between the ground value and the surface value of the intact (baseline) stimulus served as steps to ramp the surface-to-ground transition along the contour of the figure. To create gradient surface degradation, the surface-to-ground ramp in luminance (or chromaticity) was implemented within the boundary of the figure. To create sharp surface degradation, a steep shift in surface-toground luminance (or chromaticity) values was made within the figure, following the outline of the figural boundary. 
Table 1

Near-Threshold (Surface), Step, and Ground Values of Luminance (in $\mathbf{c d} / \mathrm{m}^{2}$ ) and Chromaticity (in CIE $x, y$ Coordinates) for Each of 3 Participants in Experiment 2

\begin{tabular}{|c|c|c|c|c|c|c|c|c|c|c|c|c|}
\hline \multirow[b]{3}{*}{ Observer } & & & & & \multicolumn{8}{|c|}{ Chromaticity Values } \\
\hline & \multicolumn{4}{|c|}{ Luminance Values } & \multicolumn{2}{|c|}{ Near Threshold } & \multicolumn{2}{|c|}{ Step 1} & \multicolumn{2}{|c|}{ Step 2} & \multicolumn{2}{|c|}{ Ground } \\
\hline & Near Threshold & Step 1 & Step 2 & Ground & $x$ & $y$ & $x$ & $y$ & $x$ & $y$ & $x$ & $y$ \\
\hline N.Y. & 34.6 & 34.4 & 34.1 & 33.5 & 0.361 & 0.535 & 0.362 & 0.534 & 0.364 & 0.533 & 0.366 & 0.531 \\
\hline H.W. & 34.6 & 34.4 & 34.1 & 33.5 & 0.360 & 0.536 & 0.361 & 0.535 & 0.364 & 0.533 & 0.366 & 0.531 \\
\hline F.H. & 34.6 & 34.4 & 34.1 & 33.5 & 0.360 & 0.536 & 0.361 & 0.535 & 0.364 & 0.533 & 0.366 & 0.531 \\
\hline
\end{tabular}

Note-Near-threshold values were used to create intact patterns in luminance and chromaticity tasks. Step values were used to create ramps in contour degradation and gradient surface degradation conditions (see the text for details).

nance (in luminance tasks) or chromaticity (in chromaticity tasks) were applied outward from the border of the intact pattern, each step occupying $.70^{\circ}$ of visual angle (i.e., half of the width of the intact pattern; see Figure 8B); including the additional steps, the degraded test stimulus subtended $2.8^{\circ} \times 2.8^{\circ}$ of visual angle. In the gradient surface degradation condition, the intermediate values of luminance or chromaticity were applied inward from the border of the intact pattern, each step subtending $.585^{\circ}$ of visual angle (see Figure $8 \mathrm{C}$ ); overall, the degraded pattern subtended approximately $1.4^{\circ} \times 1.4^{\circ}$ of visual angle. Finally, in the sharp surface degradation condition, the surface of the figure was shifted without steps from the near-threshold values of luminance or chromaticity to the background values, beginning $0.115^{\circ}$ inward from the border of the intact pattern. This manipulation created only a thin outline (of line width $0.115^{\circ}$ ) to define the pattern (see Figure 8D); overall, the degraded pattern subtended $1.4^{\circ} \times 1.4^{\circ}$ of visual angle.

The procedure mimicked Experiment 1, except that each session comprised five blocks of trials: one block of 32 practice trials, followed by four blocks of 160 experimental trials, one for each of the four conditions. The conditions were performed randomly in each of ten 1-h sessions, sessions alternating between luminance tasks and chromaticity tasks. The first sessions of each task were considered practice, and the data were discarded.

\section{Results}

The average sensitivity for each observer in each condition is summarized in Figure 9. Luminance tasks appear in the left panels, and chromaticity tasks in the right panels. An ANOVA was performed on sensitivity difference scores $\left(\Delta d_{\mathrm{a}}\right)$, derived as in Experiment 1, again using session as the error term. The independent variables were degradation (three levels: contour, gradient surface, and sharp surface) and task (two levels: luminance and chromaticity).

As is shown in Figure 9, the pattern of results was qualitatively similar across the 3 participants. There was a significant main effect of degradation $[F(2,6)=326.94$, $\left.M S_{\mathrm{e}}=0.02, p<.001\right]$. A Newman-Keuls post hoc test (.05 criterion level) revealed that performance loss (relative to baseline) was greatest for contour degradation $\left(\Delta d_{\mathrm{a}}=-1.62\right)$ and least for gradient surface degradation $\left(\Delta d_{\mathrm{a}}=-0.03\right)$, with sharp surface degradation falling between $\left(\Delta d_{\mathrm{a}}=-0.68\right)$. There was also a significant difference between tasks $\left[F(1,3)=77.94, M S_{\mathrm{e}}=0.06, p<.01\right]$, with degradation being more disruptive to performance in chromaticity tasks $\left(\Delta d_{\mathrm{a}}=-1.21\right)$ than in luminance tasks $\left(\Delta d_{\mathrm{a}}=-0.35\right)$. The critical finding was a significant interaction between degradation and task $[F(2,6)=330.01$, $\left.M S_{\mathrm{e}}=0.02, p<.001\right]$. As is shown in Figure 10, the great- est performance losses observed were consistent with the hypothesized specialized functions: contour degradation of luminance-defined figures $\left(\Delta d_{\mathrm{a}}=-2.15\right)$ and sharp surface degradation of chromatically defined figures $\left(\Delta d_{\mathrm{a}}=-1.89\right)$. In fact, sensitivity levels hovered close to zero in these two conditions $\left(d_{\mathrm{a}}=0.20\right.$ and 0.27 , respectively). Contour degradation also led to substantial performance loss in the chromaticity tasks $\left(\Delta d_{\mathrm{a}}=-1.09\right)$, although only about half that caused by sharp surface degradation. Minor loss was also caused by gradient surface degradation of chromatic patterns. Surface degradation (either gradient or sharp) in the luminance tasks actually produced performance gains relative to baseline, perhaps because of an increased brightness contrast in the outlined shape of the figure created by reducing the luminance within the center of the figure or because of the relatively brighter appearance of small regions (see Grossberg \& Mingolla, 1985).

\section{Discussion}

The conclusions drawn from the results of Experiment 1 are compatible with the results of Experiment 2, the two experiments employing different techniques of figural degradation. The effects of degradation in Experiment 2 were strongly dependent on the type of psychophysical information used to separate the figure from its ground, contour degradation having its most pronounced effects on the identification of luminancedefined figures and sharp surface degradation having its most pronounced effects on the identification of chromatically defined figures. This pattern of results supports the thesis that luminance and chromaticity enjoy specialized functions within a dual-mechanism system to extract the surfaces and boundaries of two-dimensional figures. Moreover, the disruptive effects of contour degradation on the identification of chromatic patterns suggest, in line with Experiment 1, that chromaticity serves as an additional, albeit secondary, source of information in extracting figural boundaries.

Contour degradation was found to be significantly more detrimental to performance than either type of surface degradation, a result not obtained in Experiment 1. The finding implies that the observers in Experiment 2 emphasized shape from boundaries in their identification decisions, a conclusion consistent with Biederman's (1987) claim for the sufficiency of edge-based represen- 


\section{Experiment 2}

\section{Luminance Tasks}

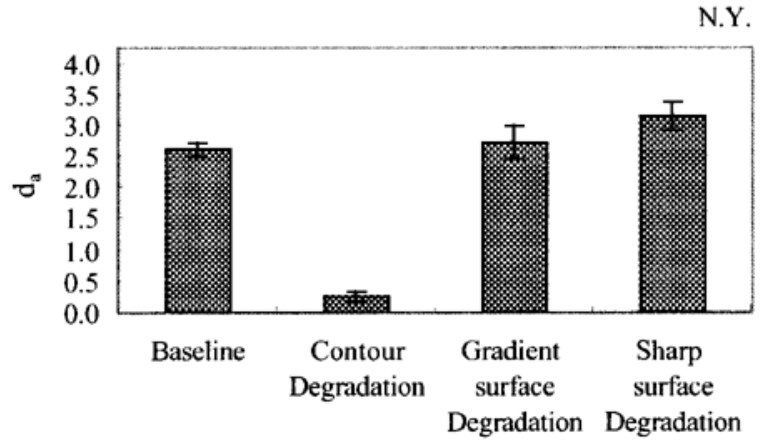

Condition

H.W.

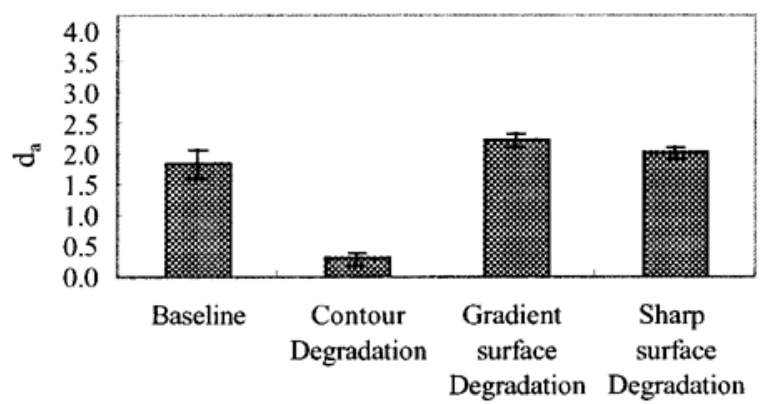

Condition

F.H.

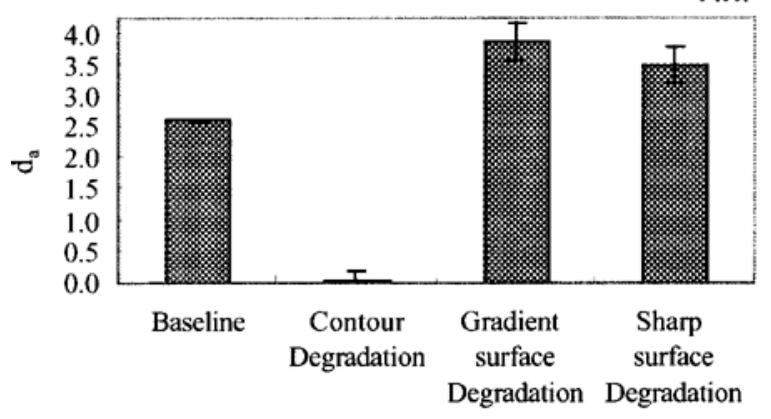

Condition

\section{Chromaticity Tasks}

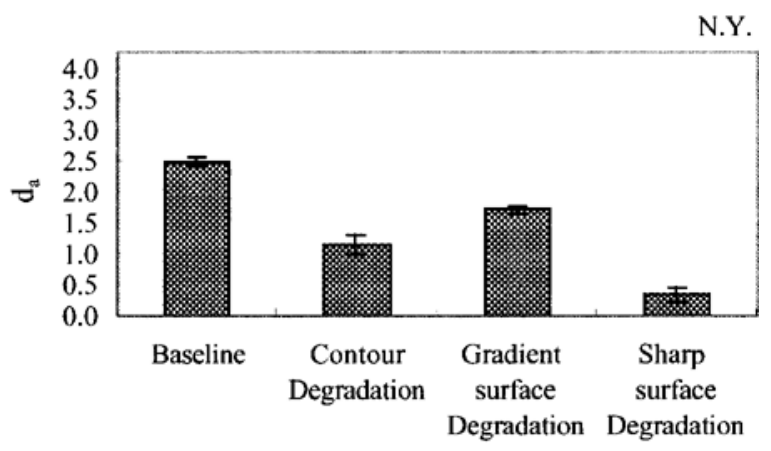

Condition

H.W.

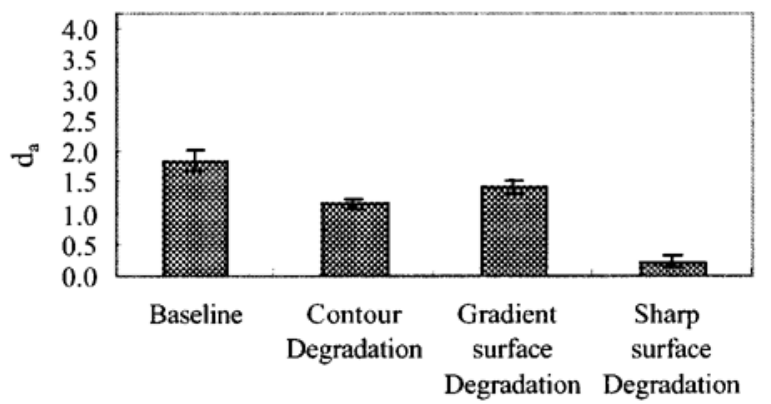

Condition

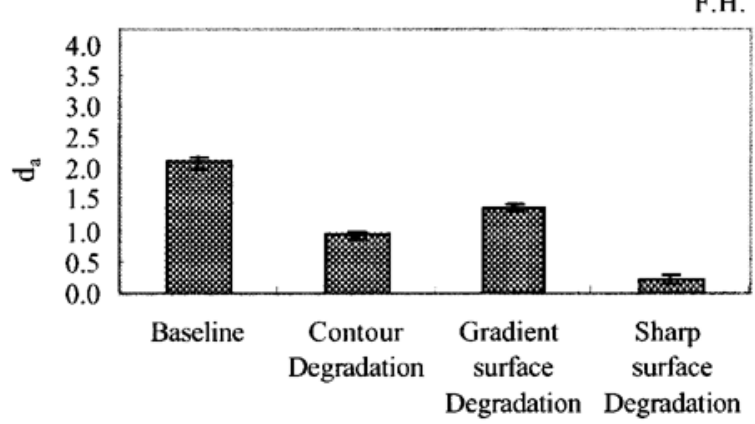

Condition

Figure 9. Average sensitivity $\left(d_{\mathrm{a}}\right)$ in luminance tasks (left panels) and chromaticity tasks (right panels) for each of 3 observers (N.Y., H.W., and F.H.) in each of the four conditions (baseline, contour degradation, gradient surface degradation, and sharp surface degradation) of Experiment 2. Performance loss (relative to baseline) was greatest for contour degradation $\left(\Delta d_{\mathrm{a}}=-1.62\right)$, least for gradient surface degradation $\left(\Delta d_{\mathrm{a}}=-\mathbf{0 . 0 3}\right)$, and intermediate for sharp surface degradation $\left(\Delta d_{\mathrm{a}}=-0.68\right)$. Performance loss was significantly greater for chromaticity tasks $\left(\Delta d_{\mathrm{a}}=-1.21\right)$ than for luminance tasks $\left(\Delta d_{\mathrm{a}}=-0.35\right)$.

tations. The effect of degradation cannot, however, be taken as evidence for the insufficiency of surface-based representations. After all, performance was significantly undercut by both types of surface degradation, particularly in the chromaticity tasks. Indeed, it is possible that surface representations were more robust than boundary representations to the effects of degradation. Or it may be that the degraded surface actually augmented certain figural cues (e.g., spatial frequency components; see Experiment 3). At best, then, the effect of degradation indicates that surfaces and boundaries are not interchangeable sources of figural information (cf. Humphrey et al., 1994). 


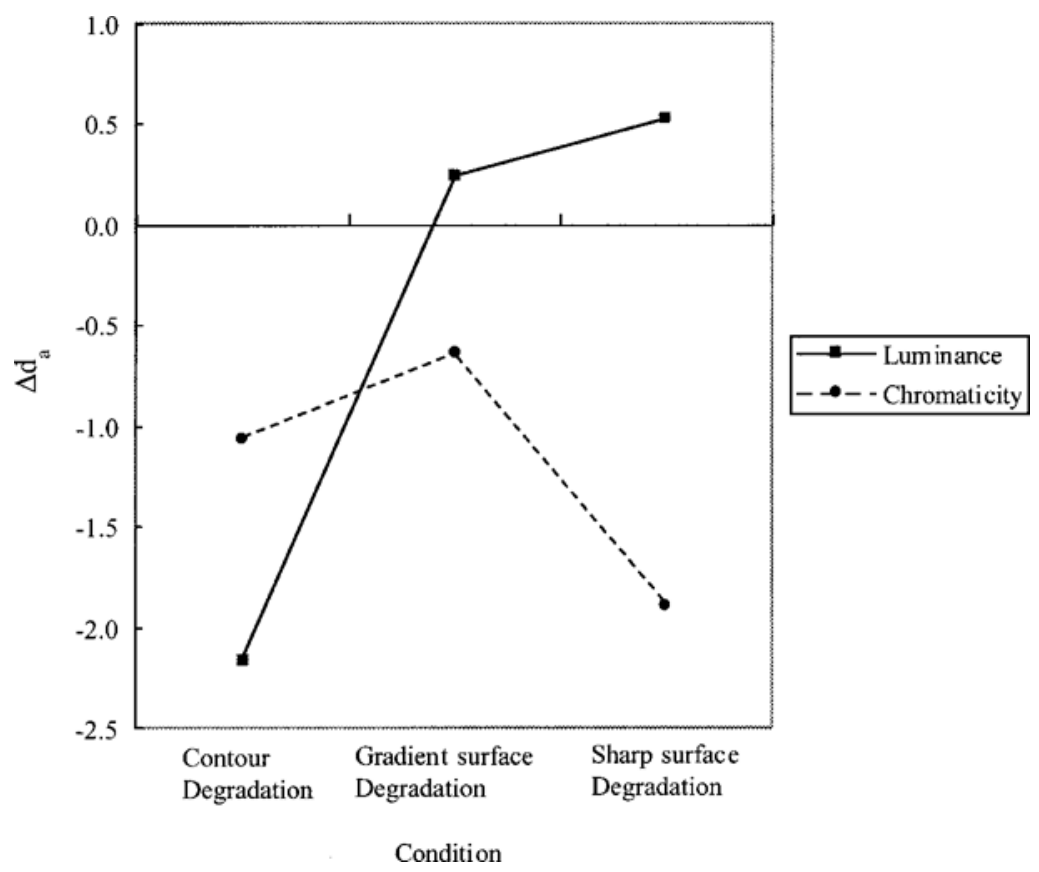

Figure 10. Average difference in sensitivity from baseline $\left(\Delta d_{\mathrm{a}}\right)$ in luminance and chromaticity tasks under the contour-degradation, gradient surface degradation, and sharp surface degradation conditions of Experiment 2. Note the crossover interaction between degradation and task: Performance in the luminance tasks was most disrupted by contour degradation, whereas performance in the chromaticity tasks was most disrupted by sharp surface degradation.

\section{EXPERIMENT 3}

The degradation procedures used in Experiment 2 altered the spatial frequency composition of the degraded patterns relative to the intact patterns. Our conclusions regarding specialized functions for luminance and chromaticity must therefore be considered in light of a possible confounding in Experiment 2 between spatial frequency and degradation condition. The panels of Figure 11 show Fourier-transform contour plots for a representative stimulus in each of the four conditions. Notice that contour degradation (panel B) eliminated the higher spatial frequencies of the intact pattern (panel A), whereas sharp surface degradation (panel D) added high spatial frequency components. Accordingly, one might interpret the relatively poor performance of the participants in the contour degradation condition of the luminance tasks as being due to the relatively poor contrast sensitivity of luminance channels to the low spatial frequencies that remained after the degradation procedure. Analogously, one might interpret the poor performance in the sharp surface degradation condition of the chromaticity tasks as being due to the relatively poor chromatic sensitivity to the high spatial frequencies added by the degradation procedure. On this account, early processing of spatial frequency components, rather than any specialized central mechanisms of boundary and surface extraction, governed the interaction between degradation and task observed in
Experiment 2. Indeed, a spatial frequency account could be applied generally to the results of the present study because, even in Experiment 1, the relative differences between conditions in spatial frequency composition persisted despite our manipulation of viewing distance (see Figure 3).

The purpose of Experiment 3 was to exclude a spatial frequency explanation of our previous results. Our approach was to match the spatial frequency characteristics of all the test stimuli by applying a low-pass spatial filter to each stimulus within each of the conditions of Experiment 2 . The cutoff frequency of the filter $(0.8 \mathrm{c} / \mathrm{deg})$ was set low enough to ensure an equivalence across conditions in stimulus spatial frequency profiles, but high enough to allow adequate contrast sensitivity along both the luminance and the chromaticity dimensions. In this way, any differences now observed between the two tasks across the three conditions could reasonably be attributed only to the selective influence of contour or surface degradation on figural identification.

\section{Method}

Participants. Two observers were tested in Experiment 3, the first author (N.Y.) and a new participant (M.K.) recruited from the ATR Human Information Processing Research Laboratories (Kyoto, Japan).

Apparatus, Stimuli, and Procedure. All the stimuli were generated by a Macintosh G3 microcomputer and displayed on a Sony GDM-F500 21-in. RGB monitor $(1,600 \times 1,200$ pixels, 256 inten- 


\section{A. Baseline}

$\mathrm{c} / \mathrm{deg}$

13.0

10.8

8.7

6.5

4.3

2.2

0.0

0.0

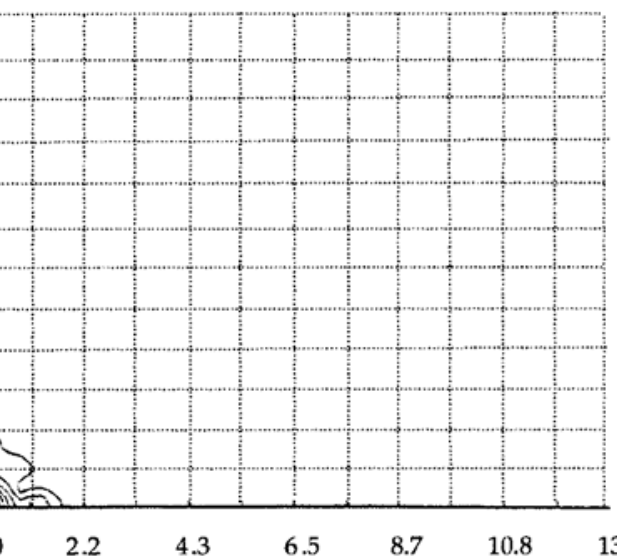

C. Gradient-surface Degradation

c/deg

13.0

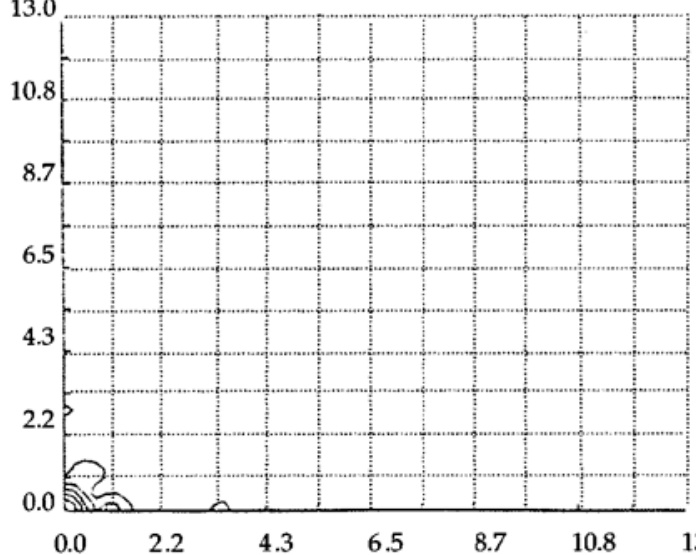

\section{B. Contour Degradation}

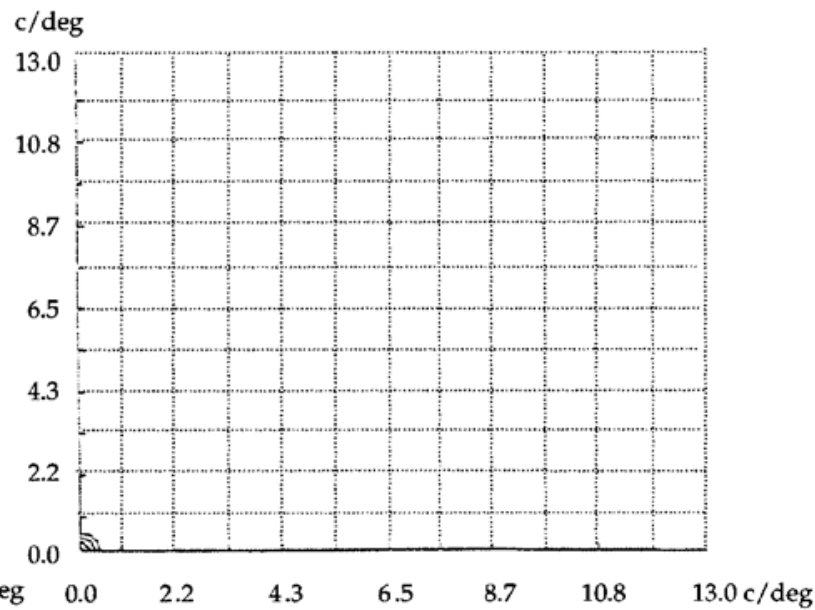

\section{Sharp-surface Degradation}

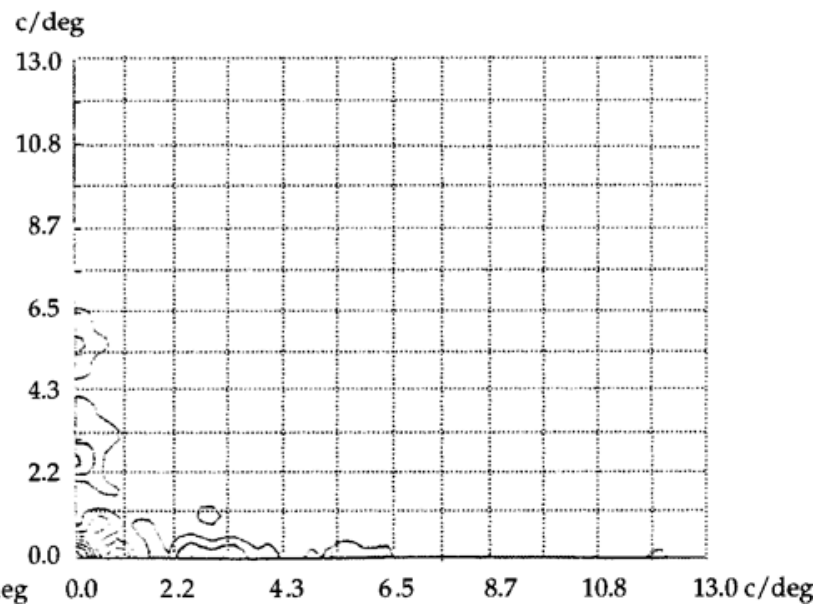

Figure 11. A Fourier-transform contour plot of one stimulus in each of the four conditions of Experiment 2: baseline (panel A), contour degradation (panel B), gradient surface degradation (panel C), and sharp surface degradation (panel D). Notice that contour degradation eliminated the higher spatial frequencies of the baseline pattern, whereas sharp surface degradation (panel D) added high spatial frequency components.

sity levels per color). Gamma correction was performed on externally measured look-up tables. As in the previous experiments, only the red and green guns of the monitor were used. The CIE chromaticity coordinates $(x, y)$ of the guns were $0.616,0.344$ (red gun) and 0.280, 0.611 (green gun).

The display characteristics were identical to those in the previous experiments (see Figure 2). To maintain Experiment 2's Nyquist rate of $13 \mathrm{c} / \mathrm{deg}$, while accommodating the higher monitor resolution of Experiment 3, the viewing distance was shortened to $37 \mathrm{~cm}$. Table 2 contains the surface, ground, and step values of luminance and chromaticity used to create the baseline and degradation conditions for each participant. On each trial, pixel values of figure and ground initially were generated invisibly, following the parameters detailed in Experiment 2. Then, prior to each stimulus presentation, the display window and its contents were low-pass filtered at a cutoff frequency of $0.8 \mathrm{c} / \mathrm{deg}$. In the luminance tasks, the filtering procedure involved performing a fast-Fourier transform (FFT; see
Press, Teukolsky, Vetterling, \& Flannery, 1992) on the pixel array of luminance values from the display window, passing the specified Fourier components and transforming the filtered CIE coordinates to RGB coordinates to present the image.

In the chromaticity tasks, the filtering procedure was slightly more complicated. All the chromaticity values were matched physically in luminance; physical isoluminance was then conf irmed psychophysically (for each participant), using flicker photometry. Color contrast $C$ at each pixel $i$ within the display window W (see Figure 2) was defined as

$$
C_{i}=\frac{L_{\mathrm{R}_{i}}-L_{\mathrm{G}_{i}}}{L_{\mathrm{R}_{i}}+L_{\mathrm{G}_{i}}}=\frac{L_{\mathrm{D}_{i}}}{L_{\mathrm{S}_{i}}}, \quad i \in \mathrm{W},
$$

where $L_{\mathrm{R}_{i}}$ and $L_{\mathrm{G}_{i}}$ are the luminance values at pixel $i$ of the red and green guns, respectively, $L_{\mathrm{D}_{i}}$ is the chromatic luminance difference at that pixel, and $L_{\mathrm{S}_{i}}$ is the chromatic luminance sum (cf. Mullen, 1985). Because the colors were physically isoluminant across the 
Table 2

Near-Threshold (Surface), Step, and Ground Values of Luminance (in $\mathbf{c d} / \mathrm{m}^{2}$ ) and Chromaticity (in CIE $x, y$ Coordinates) for Each of 2 Participants in Experiment 3

\begin{tabular}{|c|c|c|c|c|c|c|c|c|c|c|c|c|}
\hline \multirow[b]{3}{*}{ Observer } & & & & & \multicolumn{8}{|c|}{ Chromaticity Values } \\
\hline & \multicolumn{4}{|c|}{ Luminance Values } & \multicolumn{2}{|c|}{ Near Threshold } & \multicolumn{2}{|c|}{ Step 1} & \multicolumn{2}{|c|}{ Step 2} & \multicolumn{2}{|c|}{ Ground } \\
\hline & Near Threshold & Step 1 & Step 2 & Ground & $x$ & $y$ & $x$ & $y$ & $x$ & $y$ & $x$ & $y$ \\
\hline N.Y. & 34.1 & 33.9 & 33.6 & 33.0 & 0.361 & 0.546 & 0.362 & 0.545 & 0.364 & 0.544 & 0.366 & 0.542 \\
\hline M.K. & 34.6 & 34.3 & 33.7 & 33.0 & 0.358 & 0.548 & 0.360 & 0.547 & 0.363 & 0.545 & 0.366 & 0.542 \\
\hline
\end{tabular}

Note-Near-threshold values were used to create intact patterns in luminance and chromaticity tasks. Step values were used to create ramps in contour degradation and gradient surface degradation conditions (see the text for details).

display, the denominator of Equation 1 is constant across figure and ground pixels (i.e., $L_{\mathrm{S}_{i}}=k$ for all $i$ ). Thus, FFT was performed only on luminance difference scores $\left(L_{\mathrm{D}_{i}}\right)$ to extract a low-pass filtered difference value at each pixel $\left(L_{\mathrm{D}_{i}^{\prime}}{ }^{\prime}\right)$. The filtered luminance value at pixel $i$ of the red gun $\left(L_{\mathrm{R}_{i}}{ }^{\prime}\right)$ and the green gun $\left(L_{\mathrm{G}_{i}}{ }^{\prime}\right)$ was then derived by substitution:

$$
L_{\mathrm{R}_{i}}{ }^{\prime}=\frac{L_{\mathrm{S}_{i}}{ }^{\prime}-L_{\mathrm{D}_{i}}{ }^{\prime}}{2}, \quad i \in \mathrm{W},
$$

and

$$
L_{\mathrm{G}_{i}}^{\prime}=\frac{L_{\mathrm{S}_{i}}{ }^{\prime}+L_{\mathrm{D}_{i}}{ }^{\prime}}{2}, \quad i \in \mathrm{W},
$$

where $L_{\mathrm{S}_{i}}{ }^{\prime}=L_{\mathrm{S}_{i}}=k$. The arrays of $L_{\mathrm{R}_{i}}{ }^{\prime}$ and $L_{\mathrm{G}_{i}}{ }^{\prime}$ values in the display were used to draw the image and background on each trial.

All other aspects of procedure duplicated Experiment 2.

\section{Results}

Average sensitivity for each observer in each condition is summarized in Figure 12, with luminance tasks in the left panels and chromaticity tasks in the right panels. The 2 participants produced comparable patterns of performance. An ANOVA was performed on sensitivity difference scores $\left(\Delta d_{\mathrm{a}}\right)$, derived as in the previous experiments. The independent variables were degradation (three levels: contour, gradient surface, and sharp surface) and task (two levels: luminance and chromaticity). There was a significant main effect of degradation $[F(2,6)=$ 13.48, $\left.M S_{\mathrm{e}}=0.07, p<.01\right]$. A Newman-Keuls post hoc test (.05 criterion level) indicated that the decrement in performance (relative to baseline) was equivalent in the contour degradation condition $\left(\Delta d_{\mathrm{a}}=-1.42\right)$ and the sharp surface degradation condition $\left(\Delta d_{\mathrm{a}}=-1.24\right)$, but significantly less in the gradient surface degradation condition $\left(\Delta d_{\mathrm{a}}=-0.77\right)$. Moreover, the two tasks were performed equivalently $\left[F(1,3)=2.64, M S_{\mathrm{e}}=0.30\right.$, n.s. $]$. Nonetheless, the all-important interaction between degradation and task was highly significant $[F(2,6)=31.69$, $\left.M S_{\mathrm{e}}=0.05, p<.001\right]$.

The form of the interaction is revealed in Figure 13. Note here that, with one exception, figural identification of spatially filtered stimuli produced the exact relations among task and condition that were observed in Experiment 2 (cf. Figure 10). Specifically, like Experiment 2, performance in the luminance tasks was worst following contour degradation, whereas performance in the chromaticity tasks was worst following sharp surface degradation.
The one exception was that performance to surface degradation in the luminance tasks was poorer in Experiment 3 than in Experiment 2, particularly when the surface was degraded sharply. This change effectively eliminated the main effect of task, a result that we had observed in both Experiments 1 and 2 and that we had suggested might reflect the joint contribution of chromaticity information to surface and boundary representations. It now appears that a plausible alternative explanation of this result is that performance levels to surface-degraded luminance displays were artificially elevated in Experiments 1 and 2 because observers exploited the high spatial frequency components contained within these displays. By filtering out these components in Experiment 3, performance levels to all forms of degradation retreated significantly below baseline. Importantly, however, the interactive relations between task and condition were preserved across experiments.

\section{Discussion}

The results of Experiment 3 replicated the essential features of Experiment 2 under test conditions that matched the spatial frequency characteristics of all intact and degraded stimuli. Hence, early spatial filtering appears inadequate as an explanation of the differential effects of contour and surface degradation observed in these experiments. To be sure, an extensive body of evidence, both physiological (e.g., Campbell \& Robson, 1968; R. L. De Valois, Albrecht, \& Thorell, 1982) and psychophysical (e.g., Caelli \& Hubner, 1983; Field \& Nachmias, 1984; Graham, 1980; Robson \& Graham, 1981; A. Watson, Barlow, \& Robson, 1983), supports the proposition that spatial patterns are analyzed into their spatial Fourier components and detected by specialized spatial frequency channels (i.e., multiple-channel model or spatial-filtering model). Beyond this early filtering stage, however, accumulating evidence suggests a later, nonlinear stage of surface representation (Grossberg \& Mingolla, 1985; He \& Nakayama, 1994; Kanizsa, 1979; Nakayama \& Shimojo, 1992; von der Heydt, Peterhans, \& Baumgartner, 1984). He and Nakay ama claim that much texture segregation can be attributed to such postfiltering processes. On the basis of the inadequacy of a spatial frequency account of our data, we believe that the interactive effects of contour and surface degradation obtained in this study originate predominately from later visual processes. 


\section{Luminance Tasks}
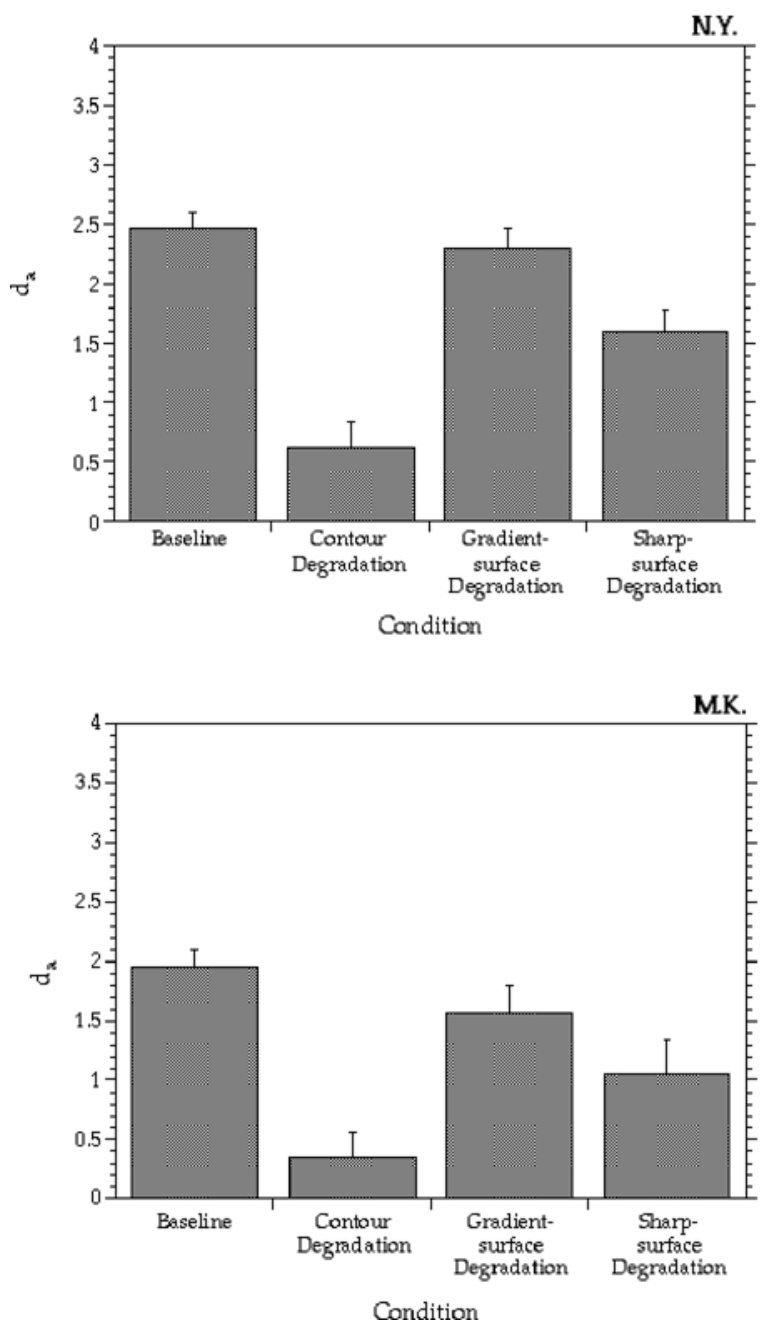

\section{Chromaticity Tasks}

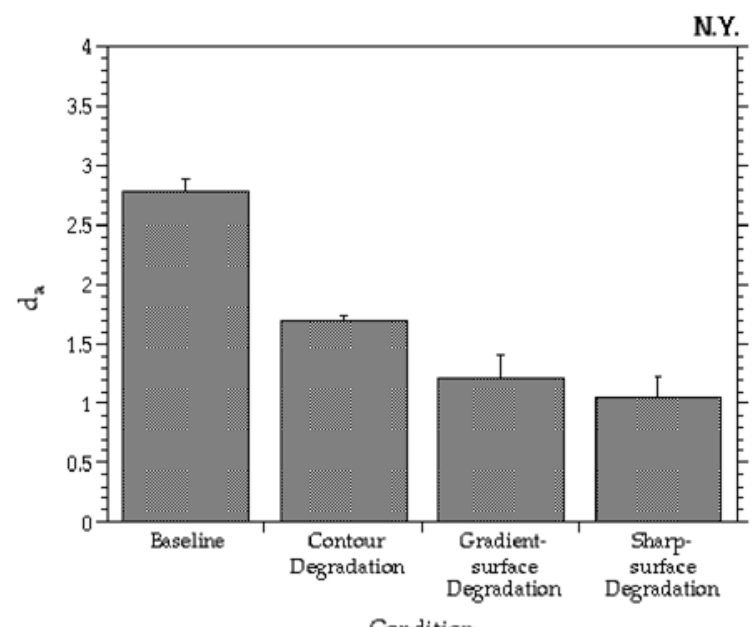

Condition

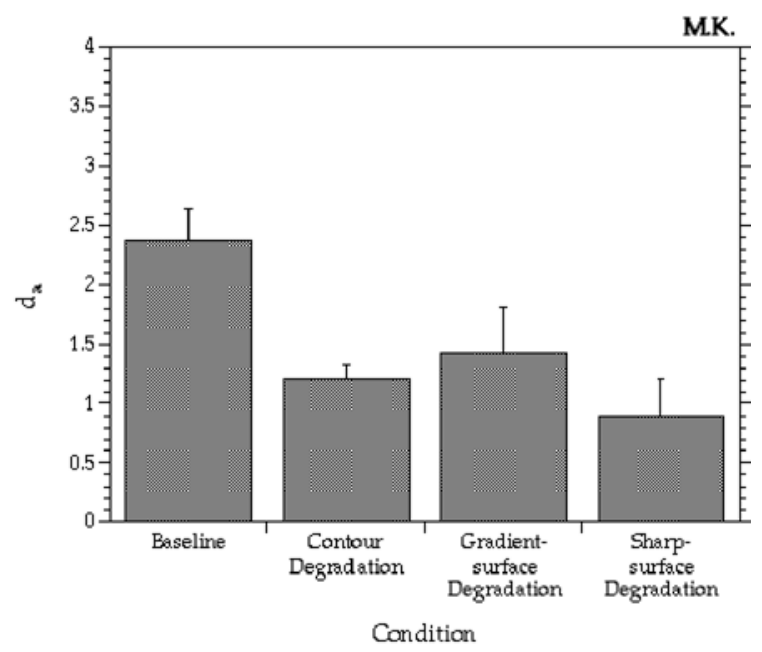

Figure 12. Average sensitivity $\left(d_{\mathrm{a}}\right)$ in luminance tasks (left panels) and chromaticity tasks (right panels) for each of $2 \mathrm{observers} \mathrm{(N.Y.}$ and M.K.) in each of the four conditions (baseline, contour degradation, gradient surface degradation, and sharp surface degradation) of Experiment 3. Performance loss (relative to baseline) was greatest for contour degradation $\left(\Delta d_{\mathrm{a}}=-1.42\right)$ and sharp surface degradation $\left(\Delta d_{\mathrm{a}}=-1.24\right)$ and least for gradient surface degradation $\left(\Delta d_{\mathrm{a}}=-0.77\right)$.

\section{GENERAL DISCUSSION}

The roles of luminance and chromaticity information in figure-ground segregation were studied in three experiments. In each experiment, observers compared the shapes of high-contrast patterns with test patterns that differed from their background in near-threshold levels of either luminance (luminance tasks) or chromaticity (chromaticity tasks). In each task, performance in a baseline condition, in which the test pattern was left intact, was compared with performance in each of several degradation conditions, in which either the contour or the surface of the figure was degraded, using either partial occlusion (Experiment 1 ) or ramping (Experiments 2 and 3 ) of figure-ground differences. In each experiment, per- formance in luminance tasks was worst when the contour was degraded, and performance in chromaticity tasks was worst when the surface was degraded.

\section{Uniqueness in Surface and Boundary Representations}

The results of the present study provide insight into several issues surrounding figure-ground perception. First, despite the close physical and conceptual ties between a figure's surface and its boundary, the present results demonstrate that, perceptually speaking, the information contained in surfaces versus boundaries makes independent contributions to figure-ground segregation. In this study, the success of segregation was defined through performance in the baseline conditions; these 


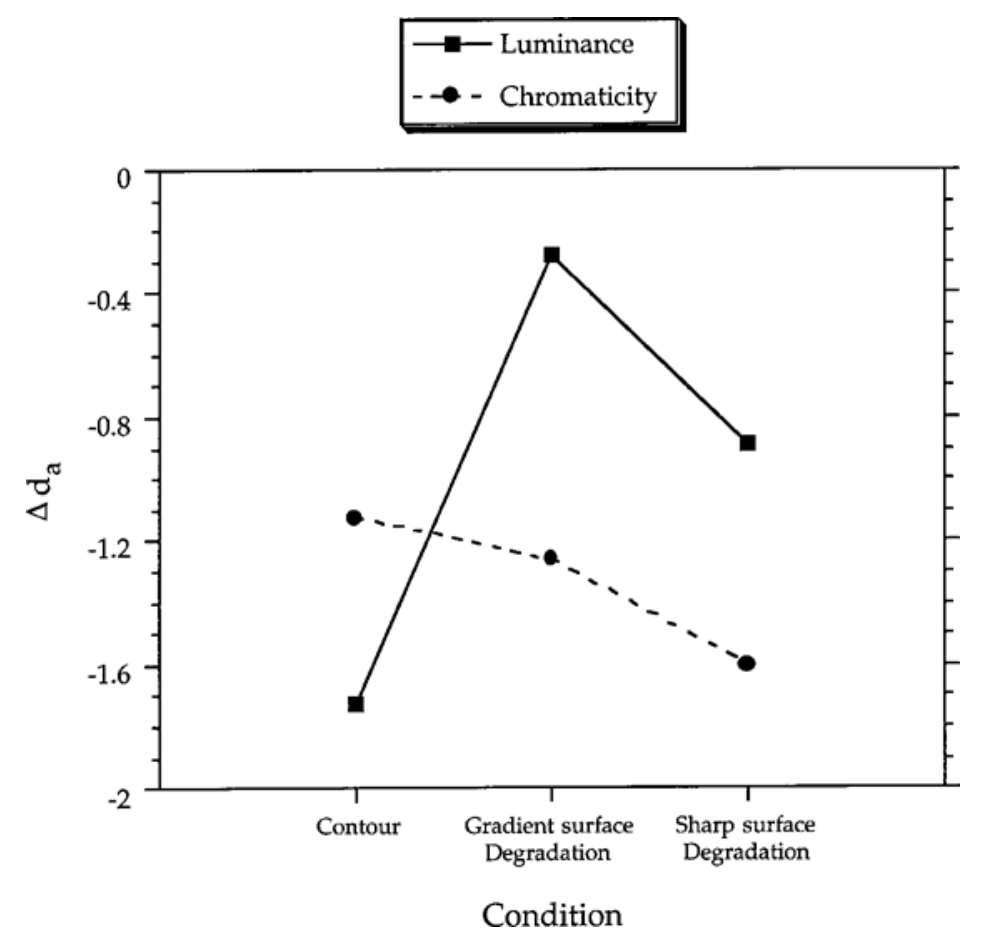

Figure 13. Average difference in sensitivity from baseline $\left(\Delta d_{\mathrm{a}}\right)$ in the luminance and chromaticity tasks under the contour degradation, gradient surface degradation, and sharp surface degradation conditions of Experiment 3. Note the crossover interaction between degradation and task: Performance in the luminance tasks was most disrupted by contour degradation, whereas performance in the chromaticity tasks was most disrupted by sharp surface degradation.

conditions were approximately matched in difficulty across figural dimensions. The baseline conditions therefore served as the standard by which all manipulations of surface and boundary qualities could be compared. We found that, depending on the figural dimension under test, degradation of either the figure's surface or its boundary could yield inferior identification performance relative to baseline, even after matching the spatial frequency compositions of the displays. We thus conclude that information contained in both the surface and the boundary are actively used in segregating a figure from its ground. Moreover, much of the extracted surface information is evidently not duplicated in the boundary, since each figural dimension was affected differently by surface versus boundary degradation.

Our results also bear on the question of whether boundary representations suffice for figure-ground segregation, as Biederman (e.g., Biederman \& Ju, 1988) has concluded. The answer appears to depend on the degree to which a figure is chromatically dissimilar from its ground. On the one hand, our results indicate that, whenever figures are isochromatic with their grounds, boundaries are necessary and sufficient for segregation: $\mathrm{Ne}-$ cessity is suggested because identification in luminance tasks suffered heavily whenever figural boundaries were degraded; sufficiency is suggested because identification in luminance tasks suffered relatively little from degrad- ing the figure's surface. ${ }^{3}$ On the other hand, boundaries were not adequate for segregation when figures were isoluminant with their grounds: Degrading the surfaces in chromaticity tasks caused a substantial loss in the observers' ability to identify figures accurately. Thus, boundary representations would appear to be unique in carrying luminance information. Moreover, because natural objects generally differ from their backgrounds in luminance (as well as chromaticity), boundary representations are sufficient and, in this sense, privileged for object recognition.

These conclusions seem at odds with those of Humphrey et al. (1994), who argued that surfaces contribute information about object identity not contained in boundary representations. Their study examined the special role of surface color in recognizing objects found in nature (e.g., fruits and vegetables). We focused instead on the adequacy of surface representations for identifying two-dimensional geometric patterns, measuring the performance loss that accompanies contour degradation. Our results showed that surface qualities by themselves are insufficient for identifying figures that are either isoluminant or isochromatic with their grounds. With isoluminant patterns, contour degradation always caused at least partial loss in performance. With isochromatic patterns, contour degradation sometimes led to near-chance performance in identification, suggesting that surface 
qualities are mostly unused in processing these patterns. Nevertheless, surface representations would appear to be unique in carrying purely chromatic information, for the results of our study suggest that perceivers mainly disregard luminance information when processing surface characteristics. In this sense, we can agree with Humphrey et al. that the surface representations of either an object or a figure are informationally distinct from its boundary representations.

\section{The Primacy of Luminance and Chromaticity Information}

A second issue elucidated by the results of this study is whether luminance information serves as the primary basis for figural identification, as Gregory $(1977,1979)$ has argued, or is, instead, of equal importance with chromaticity information, as Cavanagh $(1985,1987)$ has claimed. In one sense, symmetric contributions of luminance and chromaticity were ensured by the empirical approach we adopted: In preliminary testing, we adjusted differences along each of the figural dimensions separately until roughly equivalent performance levels were achieved for each participant across the baseline luminance and chromaticity tasks. This finding alone demonstrates that each of these dimensions can be the basis of figural identification in the absence of the other dimension. Moreover, the interactive patterns of performance obtained between the task and the degradation factors indicate that both dimensions can play important, albeit distinct, roles in figure-ground perception. Thus, the evidence would appear to point toward a general absence of primacy of one of these dimensions over the other. Still, in each experiment, we found that luminance information was privileged when the task was to identify patterns having irregular (i.e., degraded) surface qualities. In this sense, processing of luminance information may be a relatively more reliable route to accurate figure-ground perception in the real world, where surface irregularities caused by shadows or occlusions abound.

Rather than implicating a single source of information as primary, however, our results imply that perceivers actively use each first-order dimension to characterize different qualities of the figure. The observers used luminance information chiefly to locate the boundaries of the figure. They used chromaticity information primarily to locate the surface of the figure and secondarily to locate its boundaries. This pair of first-order dimensions thus serves as the perceptual basis of surface and boundary representations, as well as the basis of all second-order figural properties, including texture, motion, and spatial frequency. The crux, therefore, is that luminance and chromaticity are both primary in figure-ground perception (see Melara \& Marks, 1990).

\section{The Specialized Roles of Luminance and Chromaticity Information}

The main goal of this study was to consider the twosided hypothesis that (1) luminance information is pro- cessed selectively for the purpose of extracting a figure's boundaries, whereas (2) chromaticity information is processed selectively for the purpose of extracting a figure's surfaces. Our results were largely consistent with this hypothesis: In each of three experiments, two-dimensional patterns defined by only a luminance difference were most poorly identified when the boundary had been degraded, whereas patterns defined by only a chromatic difference were most poorly identified when the surface had been degraded. An obvious implication of the confirmed hypothesis is that figure-ground perception is supported by a dual-mechanism system, as was proposed by Rogers-Ramachandran and Ramachandran (1998), with a magnolike mechanism using luminance information to build a boundary representation, whereas a parvolike mechanism primarily uses chromaticity information to build a surface representation.

This simple picture was complicated by several findings, including evidence suggesting that luminance information has some role in surface representations, especially at farther viewing distances, and chromaticity information has some role in boundary representation at any viewing distance. One possibility is that each of the two mechanisms is preferential to a single source of information but neither mechanism is entirely selective, each being penetrable by the other first-order dimension under certain circumstances. This account effectively salvages the dualmechanism explanation.

An alternative account of our results disregards an explicit linkage with magnolike and parvolike processing mechanisms, focusing instead on how observers use perceptual evidence to reach decisions about global shape. In this paper, we have conceptualized the luminance and chromaticity dimensions as the two first-order information sources from which surface and boundary qualities arise. In nature, both luminance and chromaticity normally contribute to the creation of figural boundaries and to the transmission of surface information. Perhaps, then, perceivers actually process four different types of information to identify a figure, the four combinations of luminance or chromaticity with surfaces or boundaries: (1) the luminance difference at the boundary, (2) the luminance continuity across a surface, (3) the chromaticity difference at the boundary, and (4) the chromaticity continuity across a surface. Let us assume that these four types of information are not equal in their diagnostic value or reliability, or else that perceivers have developed certain preferences from experience (e.g., on the basis of output habitually made available by early spatial-filtering processes), with some types of information being emphasized over others when making decisions about global shape. This assumption could hold even in the present study, in which we were able to balance the perceptual differences between the two dimensions.

On this account, perceivers assign weights for combining the evidence about a figure's shape on the basis of the learned inequivalence of information (cf. E. B. Johnston, Cumming, \& Landy, 1994; Landy, Maloney, John- 
ston, \& Young, 1995). Perceivers might, for example, adopt the following rank ordering of perceptual weights: (1) luminance difference at the boundary, (2) chromatic continuity across the surface, (3) chromatic difference at the boundary, and (4) luminance continuity across the surface. Using this ordering, the stimulus degradations of surface and boundary implemented in the present study would tend to have disproportional effects on performance. On this account, then, high-level evidence accumulation, rather than lower level processing of stimulus representations, underlies the interactions between task and degradation observed in the three experiments.

Unfortunately, our set of results does not favor one of these accounts over the other. Both explanations, however, underscore an important conclusion from the present study: The visual system gives preferential treatment to specific types of stimulus information in figure-ground perception. In the dual-mechanism model, luminance and chromaticity activate separate processing pathways to derive surface and boundary representations. In the weighted-evidence model, luminance and chromaticity are most valuable diagnostically at separate locations on the figure. In both cases, luminance and chromaticity information play separate, specialized roles in distinguishing a figure from its ground. A necessary goal of future research, therefore, will be to characterize more precisely how these specialized roles arise within the visual processing pathways.

\section{REFERENCES}

Attneave, F. (1954). Some informational aspects of visual perception. Psychological Review, 61, 183-193.

BECK, J. (1966). Perceptual grouping produced by changes in orientation and shape. Science, 154, 538-540.

BECK, J. (1982). Textural segmentation. In J. Beck (Ed.), Organization and representation in perception (pp. 285-317). Hillsdale, NJ: Erlbaum.

Bender, M. B., \& Teuber, H. L. (1946). Phenomena of fluctuation extinction and completion in visual perception. Archives of Neurology \& Psychiatry, 55, 627-658.

Biederman, I. (1987). Recognition-by-components: A theory of human image understanding. Psychological Review, 94, 115-147.

Biederman, I., \& Cooper, E. E. (1992). Size invariance in visual object priming. Journal of Experimental Psychology: Human Perception \& Performance, 18, 121-133.

Biederman, I., \& Ju, G. (1988). Surface versus edge-base determinants of visual recognition. Cognitive Psychology, 20, 38-64.

Boynton, R. M., Hay hoe, M. M., \& MacLeod, D. I. A. (1977). The gap effect: Chromatic and achromatic visual discrimination as affected by field separation. Optica Acta, 24, 159-177.

Buser, P., \& Imbert, M. (1992). Vision (R. H. Kay, Trans.). Cambridge, MA: MIT Press. (Original work published 1987)

Caelli, T., \& Hubner, M. (1983). On the efficient two-dimensional coding characteristics of spatial vision. Vision Research, 23, 10531055.

Campbell, F. W., \& Robson, J. G. (1968). Application of Fourier analysis to the visibility of gratings. Journal of Physiology, 197, 551-566.

Cavanagh, P. (1985). Depth and surface inferences in line drawings. Journal of the Optical Society of America A, 2, P51.

CAVANAGH, P. (1987). Reconstructing the third dimension: Interactions between color, texture, motion, binocular disparity, and shape. Computer Vision, Graphics, \& Image Processing, 37, 171-195.

Cavanagh, P., Arguin, M., \& Treisman, A. (1990). Effect of surface medium on visual search for orientation and size feature. Journal of
Experimental Psychology: Human Perception \& Performance, 16, 479-491.

Cavanagh, P., \& Leclerc, Y. G. (1989). Shape from shadows. Journal of Experimental Psychology: Human Perception \& Performance, 15, 3-27.

Christou, C., Koenderink, J. J., \& van Doorn, A. J. (1996). Surface gradients, contours and the perception of surface attitude in images of complex scenes. Perception, 25, 701-713.

Cole, G. R., Stromeyer, C. F., III, \& Kronauer, R. E. (1990). Visual interactions with luminance and chromatic stimuli. Journal of the Optical Society of America A, 7, 128-140.

Cornsweet, T. M. (1970). Visual perception. New York: Academic Press.

De VAlois, K. K., \& Switkes, E. (1983). Simultaneous masking interactions between chromatic and luminance gratings. Journal of the Optical Society of America, 73, 11-18.

De Valois, R. L., Albrecht, D. G., \& Thorell, L. G. (1982). Spatial frequency selectivity of cells in macaque visual cortex. Vision Research, 22, 545-559.

De Valois, R. L., \& De Valois, K. K. (1988). Spatial vision. New York: Oxford University Press.

De Valois, R. L., Morgan, H., \& Snodderly, D. M. (1974). Psychophysical studies of monkey vision: III. Spatial luminance contrast sensitivity tests of macaque and human observers. Vision Research, 14, 75-81.

De Yoe, E. A., \& van Essen, D. C. (1988). Current processing streams in monkey visual cortex. Trends in Neurosciences, 11, 219-226.

Dorfman, D. D., \& Alf, E. (1969). Maximum-likelihood estimation of parameters of signal detection theory and determination of confidence intervals: Rating method data. Journal of Mathematical Psychology, 6, 487-496.

Duncan, J., \& Nimmo-Smith, I. (1996). Objects and attributes in divided attention: Surface and boundary systems. Perception \& Psychophysics, 58, 1076-1084.

Enns, J. T., \& Rensink, R. A. (1991). VSearch Color: Full-color visual search experiments on the Macintosh II. Behavior Research Methods, Instruments, \& Computers, 23, 265-272.

EsKew, R. T., JR., \& Boynton, R. M. (1987). Effects of fields, area and configuration on chromatic and border discriminations. Vision Research, 27, 1835-1844.

Field, D., \& Nachmias, J. (1984). Phase reversal discrimination. Vision Research, 24, 333-340.

Fiser, J., \& BIEDERMAN, I. (1995). Size invariance in visual object priming of gray-scale images. Perception, 24, 741-748.

GARNER, W. R. (1974). The processing of information and structure. Hillsdale, NJ: Erlbaum.

Gassel, M. M., \& Williams, D. (1963). Visual function in patients with homonymous hemianopia: Pt. III. The completion phenomenon: Insight and attitude to the defect and visual functional efficiency. Brain: A Journal of Neurology, 86, 229-260.

Gerrits, H. J. M., \& Timmerman, G. J. M. E. N. (1969). The filling-in process and information processing in patients with retinal scotomata. Vision Research, 9, 439-442.

GiBson, J. J. (1966). The senses considered as perceptual systems. Boston: Houghton Mifflin.

GraHAm, N. (1980). Spatial-frequency channel in human vision: Detecting edges without edge detectors. In C. S. Harris (Ed.), Visual coding and adaptability (pp. 215-262). Hillsdale, NJ: Erlbaum.

GraHAM, N. (1989). Visual pattern analyzers. New York: Oxford University Press.

Granger, E. M., \& Heurtley, J. C. (1973). Visual chromaticitymodulation transfer function. Journal of the Optical Society of America, 63, 1173-1174.

Green, D. M., \& Swets, J. A. (1966). Signal detection theory and psychophysics. New York: Wiley.

Greenhouse, S. W., \& GeIsSER, S. (1959). On methods in the analysis of profile data. Psychometrika, 24, 95-112.

GREGORY, R. L. (1977). Vision with isoluminant colour contrast: 1. A projection technique and observations. Perception, 6, 113-119.

GREGORY, R. L. (1979). Stereo vision and isoluminance. Proceedings of the Royal Society of London: Series B, 204, 467-476. 
Grossberg, S. (1987). Cortical dynamics of three-dimensional form, color, and brightness perception: II. Binocular theory. Perception \& Psychophysics, 41, 117-158.

Grossberg, S., \& Mingolla, E. (1985). Neural dynamics of form perception: Boundary completion, illusory figures, and neon color spreading. Psychological Review, 92, 173-211.

Grossberg, S., \& PessoA, L. (1998). Texture segregation, surface representation, and figure-ground separation. Vision Research, 38, 2657-2684.

Grossberg, S., \& Todorović, D. (1988). Neural dynamics of 1-D and 2-D brightness perception: A unified model of classical and recent phenomena. Perception \& Psychophysics, 43, 241-277.

Hartmann, G. W. (1935). Gestalt psychology: A survey of facts and principles. Westport, CT: Greenwood.

He, Z. J., \& Nakayama, K. (1994). Perceiving texture: Beyond filtering. Vision Research, 34, 151-162.

Humphrey, G. K., Goodale, M. A., Jakobson, L. S., \& Servos, P. (1994). The role of surface information in object recognition: Studies of a visual form agnosic and normal subjects. Perception, 23, 1457-1481.

Johnston, A., Hill, H., \& Carman, N. (1992). Recognising faces: Effects of lighting direction, inversion, and brightness reversal. Perception, 21, 365-375.

Johnston, E. B., Cumming, B. G., \& LANDy, M. S. (1994). Integration of stereopsis and motion shape cues. Vision Research, 34, 2259-2275.

JuLESZ, B. (1964). Binocular depth perception without familiarity cues. Science, 145, 356-362.

Julesz, B. (1984). Toward an axiomatic theory of preattentive vision. In G. M. Edelman, W. E. Gall, \& W. M. Cowan (Eds.), Dynamic aspects of neocortical function (pp. 585-711). New York: Wiley.

Kanizsa, G. (1979). Organization in vision: Essays in Gestalt perception. New York: Praeger.

KöHLER, W. (1920). Die physischen Gestalten in Ruhe und im stationaren Zustand [Physical gestalts during passive and immobile states]. Braunschweig: Vieweg.

KöHLER, W. (1958). The present situation in brain physiology. American Psychologist, 13, 150-154.

KöHLER, W., \& HELD, R. (1949). The cortical correlates of pattern vision. Science, 110, 414-419.

Landy, M. S., Maloney, L. T., Johnston, E. B., \& Young, M. (1995). Measurement and modeling of depth cue combination: In defense of weak fusion. Vision Research, 35, 389-412.

LASHLEY, K. S. (1941). Patterns of cerebral integration indicated by the scotomas of migraine. Archives of Neurology \& Psychiatry, 46, 331339.

Livingstone, M. S., \& Hubel, D. H. (1987). Psychophysical evidence for separate channels for the perception of form, color, movement, and depth. Journal of Neuroscience, 7, 3416-3468.

Livingstone, M. S., \& Hubel, D. H. (1988). Segregation of form, color, movement, and depth: Anatomy, physiology, and perception. Science, 240, 740-749.

Logothetis, N. K., \& Pauls, J. (1995). Psychophysical and physiological evidence for viewer-centered object representations in the primate. Cerebral Cortex, 5, 270-288.

Logothetis, N. K., Pauls, J., \& Poggio, T. (1995). Shape representation in the inferior temporal cortex of monkeys. Current Biology, $\mathbf{5}$ 552-563.

Macmillan, N. A., \& Creelman, C. D. (1991). Detection theory: A user's guide. Cambridge: Cambridge University Press.

MARr, D. (1982). Vision. San Francisco: Freeman.

Maunsell, J. H. R. \& Newson, W. T. (1987). Visual processing in monkey extrastriate cortex. Annual Review of Neuroscience, 10, 363 401.

McIlhagga, W. H., \& Mullen, K. T. (1996). Contour integration with colour and luminance contrast. Vision Research, 36, 1265-1279.

MCNicol, D. (1972). A primer of signal detection theory. London: Allen \& Unwin.

Melara, R. D., \& Marks, L. E. (1990). Perceptual primacy of dimensions: Support for a model of dimensional interaction. Journal of Experimental Psychology: Human Perception \& Performance, 16, 398414

Merigan, W. H., \& Maunsell, J. H. R. (1993). How parallel are the primate visual pathways? Annual Review of Neuroscience, 16, 369402.

Mullen, K. T. (1985). The contrast sensitivity of human colour vision to red-green and blue-yellow chromatic gratings. Journal of Physiology, 359, 381-400.

Nakayama, K., \& Shimojo, S. (1992). Experiencing and perceiving visual surface. Science, 257, 1357-1363.

Nakayama, K., Shimojo, S., \& Ramachandran, V. S. (1990). Transparency: Relation to depth, subjective contours, luminance, and neon color spreading. Perception, 19, 497-513.

OstergaARD, A. L., \& DAVIDOFF, J. B. (1985). Some effects of color on naming and recognition of objects. Journal of Experimental Psychology: Learning, Memory, \& Cognition, 11, 579-587.

PALMer, S. E. (1982). Symmetry, transformation, and the structure of perceptual systems. In J. Beck (Ed.), Organization and representation in perception (pp. 95-144). Hillsdale, NJ: Erlbaum.

Palmer, S. E. (1991). Goodness, Gestalt, groups, and Garner: Local symmetry subgroups as a theory of figural goodness. In G. R. Lockhead \& J. R. Pomerantz (Eds.), The perception of structure: Essays in honor of Wendell R. Garner (pp. 23-39). Washington, DC: American Psychological Association.

Paradiso, M. A., \& NaKayama, K. (1991). Brightness perception and filling-in. Vision Research, 31, 1221-1236.

Press, W. H., Teukolsky, S. A., Vetterling, W. T., \& Flannery, B. P. (1992). Numerical recipes in C: The art of scientific computing (2nd ed.). New York: Cambridge University Press.

Price, C. J., \& Humphreys, G. W. (1989). The effects of surface detail on object categorization and naming. Quarterly Journal of Experimental Psychology, 41A, 797-827.

RAMACHANDRAN, V. S. (1992). Perception: A biological perspective. In G. A. Carpenter \& S. Grossberg (Eds.), Neural networks for vision and image processing (pp. 45-91). Cambridge, MA: MIT Press.

RamachandRan, V. S., \& Gregory, R. L. (1991). Perceptual filling-in of artificially induced scotomas in human vision. Nature, 350, 669702.

Ramachandran, V. S., Gregory, R. L., \& Aiken, W. (1993). Perceptual fading of visual texture borders. Vision Research, 33, 717-721.

RAMACHANDRAN, V. S., \& Rogers-RamachandRan, D. C. (1991). Phantom contours: A new class of visual patterns that selectively activates the magnocellular pathway in man. Bulletin of the Psychonomic Society, 29, 391-394.

Redies, C., \& Spillmann, L. (1981). The neon color effect in the Ehrenstein illusion. Perception, 10, 667-681.

Robson, J. G., \& Graham, N. (1981). Probability summation and regional variation in contrast sensitivity across the visual field. Vision Research, 21, 409-418.

Rogers-Ramachandran, D. C., \& Ramachandran, V. S. (1998). Psychophysical evidence for boundary and surface systems in human vision. Vision Research, 38, 71-77.

Rubin, E. (1915). Synsoplevde figurer [Visually perceived figures]. Copenhagen: Gyldendal.

Servos, P., Goodale, M. A., \& Humphrey, G. K. (1993). The drawing of objects by a visual form agnosic: Contribution of surface properties and memorial representations. Neuropsychologia, 31, 251-259.

SHAPLEY, R. (1990). Visual sensitivity and parallel retinocortical channels. Annual Review of Psychology, 41, 635-658.

Swets, J. A., \& Pickett, R. M. (1982). Evaluation of diagnostic systems. New York: Academic Press.

Tanaka, J. W., \& Presnell, L. M. (1999). Color diagnosticity in object recognition. Perception \& Psychophysics, 61, 1140-1153.

Theeuwes, J. (1992). Perceptual selectivity for color and form. Perception \& Psychophysics, 51, 599-606.

Treisman, A. M. (1988). Features and objects: The fourteenth Bartlett memorial lecture. Quarterly Journal of Experimental Psychology, 40A, 201-237.

Treisman, A. [M.], \& Gelade, G. (1980). A feature-integration theory of attention. Cognitive Psychology, 12, 97-136.

Ullman, S. (1984). Visual routines. Cognition, 18, 97-159.

Ungerleider, L. G., \& Mishrin, M. (1982). Two cortical visual systems. In D. J. Ingle, M. A. Goodale, \& R. J. W. Mansfield (Eds.), Analysis of visual behavior (pp. 549-586). Cambridge, MA: MIT Press. 
VAN ESSEN, D. C. (1985). Functional organization of primate visual cortex. In A. Peters \& E. G. Jones (Eds.), Cerebral cortex: 3 (pp. 259329). New York: Plenum.

van Essen, D. C., Maunsell, J. H. R., \& Bixby, J. L. (1981). Organization of the extrastriate visual areas of the macaque monkey. In C. N. Woolsey (Ed.), Cortical sensory organization: Vol. 2. Multiple visual areas (pp. 157-170). Clifton, NJ: Humana Press.

van TuiJl, H. F. J. M. (1975). A new visual illusion: Neonlike color spreading and complementary color induction between subjective contours. Acta Psychologia, 39, 441-445.

von der Heydt, R., Peterhans, E., \& Baumgartner, G. (1984). Illusory contours and cortical neuron responses. Science, 224, 12601262.

Ware, C., \& Cowan, W. B. (1983). The chromatic Cornsweet effect. Vision Research, 23, 1075-1077.

Watanabe, T., \& Sato, T. (1989). Effect of luminance contrast on color spreading and illusory contour in the neon color spreading effect. Perception \& Psychophysics, 45, 427-430.

Watson, A., Barlow, H. B., \& Robson, J. G. (1983). What does the eye see best? Nature, 302, 419-422.

Watson, D. G., \& Humphreys, G. W. (1999). Segmentation on the basis of linear and local rotational motion: Motion grouping in visual search. Journal of Experimental Psychology: Human Perception \& Performance, 25, 70-82.

Wertheimer, M. (1912). Experimentelle Studien über das Sehen von Bewegung [Experimental studies of motion perception]. Zeitschrift für Psychologie, 60, 161-265.

Witkin, A. P., \& Tenenbaum, J. M. (1983). On the role of structure in vision. In J. Beck, B. Hope, \& A. Rosenfeld (Eds.), Human and machine vision (pp. 481-543). New York: Academic Press.

Wurm, L. H., Legge, G. E., Isenberg, L. M., \& LuebKer, A. (1993). Color improves object recognition in normal and low vision. Journal of Experimental Psychology: Human Perception \& Performance, 19, 899-911.

Yantis, S. (1995). Perceived continuity of occluded visual objects. Psychological Science, 6, 182-186.

YounG, M. P. (1995). Open questions about the neural mechanisms of visual pattern recognition. In M. S. Gazzaniga (Ed.), The cognitive neurosciences (pp. 463-474). Cambridge, MA: MIT Press.
ZEKI, S. (1978). Uniformity and diversity of structure and function in rhesus monkey prestriate visual cortex. Journal of Physiology, 277, 273-290.

ZEKI, S. (1993). A vision of the brain. Oxford: Blackwell Scientific. ZEKI, S., \& SHIPP, S. (1988). The functional logic of cortical connections. Nature, 335, 311-317.

\section{NOTES}

1. We recognize that Biederman and Ju's (1988) study, like several other studies described in this section, was concerned with object recognition, rather than with figure-ground perception per se. Thus, evidence from these studies for the privileged status of boundaries or surfaces may apply only to the extraction of long-term knowledge regarding familiar objects or their properties (Logothetis \& Pauls, 1995; Logothetis, Pauls, \& Poggio, 1995). Nevertheless, we consider this evidence an important piece of the more general argument that boundaries and surfaces can enjoy separate roles in the processes distinguishing one aspect of the visual scene (e.g., figure) from another (e.g., ground; see Young, 1995).

2. We are not suggesting that the parvocellular pathway is insensitive to achromatic information or that the two pathways are fully selfcontained (see Merigan \& Maunsell, 1993). In fact, as we will discuss later, evidence from the present study indicates that both luminance and chromaticity information contribute to the extraction of both the contours and the surfaces of figures, albeit in vastly differing degrees.

3 . It is conceivable that (hypothetical) visual displays completely lacking in physical boundaries might still contain sufficient perceptual information for successful figural segregation. However, the extremely poor identification performance evinced by the observers in the contourdegraded luminance tasks of Experiment 3-where ramping ensured that the image surface changed only gradually from the background, whereas spatial filtering retained only low-frequency spatial changes in the display - strongly suggests that boundary removal exacts a heavy toll on the mechanisms that segregate isochromatic images.

(Manuscript received July 20, 1999; revision accepted for publication August 2, 2000.) 